Florida International University FIU Digital Commons

\title{
Intranational Trade and Regional Tax Rates: A Welfare Analysis on the U.S. Economy
}

Hakan Yilmazkuday

Department of Economics, Florida International University, dyilmazk@fiu.edu

Follow this and additional works at: https://digitalcommons.fiu.edu/economics_wps

\section{Recommended Citation}

Yilmazkuday, Hakan, "Intranational Trade and Regional Tax Rates: A Welfare Analysis on the U.S. Economy" (2011). Economics Research Working Paper Series. 15.

https://digitalcommons.fiu.edu/economics_wps/15 


\title{
Intranational Trade and Regional Tax Rates: A Welfare Analysis on the U.S. Economy
}

\author{
Hakan Yilmazkuday*
}

\begin{abstract}
This paper analyzes the effects of personal tax rates on macroeconomic variables at regional and national levels through a general equilibrium trade model with private and public sectors, migrating individuals, intermediate inputs and final goods trade, and an analytical solution. The regional model can explain state-level variables in the U.S. almost perfectly. The counterfactuals on the U.S. economy suggest that a nationwide increase in the statelevel dividend-income tax rates would be the best option to expand the private sector, tax revenues, and, most importantly, the individual welfare in all states; a nationwide increase in the state-level wage-income tax rates would hurt the economy in all states; property and sales taxes have fewer effects on the U.S. economy. The results are mainly driven by intermediate input trade.
\end{abstract}

JEL Classification: H24, H71, R12, R13, R32

Key Words: Regional Taxes, Trade, Public Sector, Private Sector, the U.S.

\footnotetext{
*Department of Economics, Florida International University, Miami, FL 33199, USA; e-mail: skuday@gmail.com
} 


\section{Introduction}

Tax rates are the key ingredients of public policy and affect the allocation of resources through optimizing agents in a micro-founded setup. In a world with many types of taxes and high interaction among macroeconomic variables, it is hard to determine which tax type is the best option for the economy, because an economy may benefit or suffer from a tax rate change. One should be careful while defining economy and best: The best nationwide policy may not be the best one for all regions of the economy, or the best local policy may not be the best one for the national economy. Therefore, regional policy implications should be obtained through investigating regional tax rates and (i) the effects of a nationwide tax rate change on all regions (i.e., nationwide and local effects of nationwide policy), (ii) the effects of a tax rate change in a region on other regions, and thus, the national economy (i.e., nationwide effects of local policy), (iii) the effect of a nationwide tax rate change on each region (local effects of nationwide/federal policy), (iv) the effect of a tax rate change in a region on that region (i.e., local effects of local policy). Such an investigation cannot be achieved through a national macro (i.e., an aggregated-level) analysis; one rather needs a regional (i.e., a disaggregated-level) analysis that considers interactions among regions of a nation.

Determining optimal regional tax rates is one of the biggest issues at the regional level, because regional tax rates are the main policy tools of regional governments; e.g., consider the states of the U.S.: The recent national recession had such a devastating effect on state finances in the U.S. that states took in $\$ 87$ billion less in tax revenue from October 2008 through September 2009 than they collected in the previous 12 months; this corresponds to a decline of 11 percent, the steepest on record, resulted from the impact on tax collections of reduced wages and lowered economic activity (see Johnson et al., 2010). The requirement that states have balanced budgets has increased the pressure on states to deal with the unprecedented revenue shortfalls in a variety of ways; to recoup lost revenue, states have taken actions such as increasing rates. The story is very similar to the slowdown of the U.S. economy in 2001 when many states raised taxes to balance their budgets (see Orszag and Stiglitz, 2001). However, in a world of interacting regions, which type of tax is the best policy tool in each state to improve its economy, or is there any nationwide/federal policy that can lead to improvement in all states? Answering this question requires considering interactions among regions of a nation (or union) through a general equilibrium analysis that will solve for all regional variables simultaneously with optimizing agents at the regional level; nationwide variables should be implied through such a regional analysis. 
This paper introduces a general equilibrium regional trade model to investigate possible effects of regional tax rates on the macroeconomic variables at the regional and national levels in the long run. The model consists of a finite number of regions, finite number of individuals in each region, a private monopolistically-competitive firm in each region, a non-profit public sector (i.e., government) in each region, region-specific (wage-income, dividend-income, property, sales) taxes, intermediate inputs and final goods trade across regions, and migrating individuals. As will be evident below, the modeling strategy that we follow is not arbitrary, and it is partly to capture the economic interactions in the U.S. economy (e.g., interregional trade in final consumption goods and intermediate inputs), partly to investigate dividend-income taxes (e.g., profits through monopolistically-competitive firms), partly to obtain an analytical solution that considers migration (e.g., finite numbers of regions and individuals), and partly for simplicity (e.g., a non-profit public sector). The private firm in each region is perfectly specialized in the production of a good/variety so that it has a market power to set its price with a markup over its marginal cost where the markup is a function of the elasticity of substitution across private-sector goods. Public sector in each region produces a unique public good until the total costs are equalized to total taxes collected in that region. The total amount of the public good in each region is equally shared among the individuals in that region; the public good is nontradable. Both private and public sectors in each state have constant returns to scale production technologies that use labor and intermediate inputs purchased from the private sector in all regions as factors of production and are subject to region-specific technology levels. Individuals have utilities from final goods of the private sector coming from all regions, the unique public good in their region, and the property/land that they live at, and they have disutility from supplying labor to either private or public firms; the regional taxes come into the picture in the budget constraint of the individuals. There is a unique labor market in the nation/union (i.e., aggregation of all regions) where the total labor demand coming from private and public sectors are matched with the labor supply coming from the individuals in all regions; i.e., individuals may live and work in different regions. The total profit of monopolistically-competitive private sector in all regions is equally shared among all individuals in all regions. Because each private firm (in each region) supplies its traded good to individuals in all regions (as a final consumption good), to all private firms in all regions (as an intermediate input), and to the public sector in all regions (as an intermediate input), there are interactions between the public sector and the private sector in all regions. The exports of 
each private firm (in each region) are subject to iceberg trade costs which is important to include geographical characteristics of regions into the model. The land as a factor of production has been extensively used and analyzed in the literature; however, to focus on fewer-analyzed individual-tax effects at the regional and national levels, this paper does not consider location choice of firms or corporate taxes but controls for the land used by firms through introducing a region-specific parameter for the fraction of land used by individuals. This fraction is further estimated through the empirical analysis. The land in each region is owned by the public sector in that region, and its revenue is an additional source for the production of the public good.

In equilibrium, private-sector goods, public-sector goods, property/land, and labor markets are cleared, and individual-level utilities are equalized through migration of individuals across regions. Region-specific tax rates, technology levels (of private and public sectors), iceberg trade costs, land sizes, and the total population in all regions are the exogenous variables of the model, while the elasticity of substitution across goods and the region-specific fractions of land that are supplied to individuals are model parameters. The model can be analytically solved; i.e., variables at the regional and national levels can be expressed in terms exogenous variables and model parameters. The state-level data of production, consumption, government expenditure, and interstate bilateral trade from the U.S. are explained almost perfectly by the model. Since the model is a regional one, it is rich enough for the U.S. counterfactuals at the state and national levels.

This paper focuses on the effects of personal (individual) tax rates on the U.S. macroeconomic variables: The best policy tools (among wage-income, dividend-income, property, and sales taxes) to expand the private sector, tax revenues (i.e., the public sector), and the individual welfare are investigated at the state and national levels. The results have public-policy implications for the U.S. Federal Government: (i) a 1\% nationwide increase in dividend-income tax rates would result in about $5.25 \%$ raise in welfare measured by individual utility; (ii) a $1 \%$ nationwide increase in wage-income tax rates would result in about $3.77 \%$ fall in welfare; (iii) property and sales taxes have fewer effects on the U.S. economy (i.e., a 1\% nationwide increase in property taxes results in $0.43 \%$ raise in welfare, while a $1 \%$ nationwide increase in sales taxes results in 0.26 fall in welfare) We show that these implications are mostly due to allowing for intermediate input trade between private and public sectors; i.e., with a higher tax revenue, the public sector produces more output and hence purchases more intermediate inputs from the private sector, which, in turn, raises overall output and welfare in the economy. When we shut down intermediate input trade, the numbers 
turn such that (i) a $1 \%$ nationwide increase in dividend-income tax rates would result in about $2.55 \%$ fall in welfare measured by individual utility; (ii) a $1 \%$ nationwide increase in wage-income tax rates would result in about $0.58 \%$ fall in welfare; (iii) a $1 \%$ nationwide increase in sales taxes would result in $2.42 \%$ fall in welfare. Therefore, considering intermediate inputs plays an important role in the determination of optimal public policy. The results also have public-policy implications for the individual state governments in the U.S.; e.g., California would benefit significantly from an increase in any tax type but wage-income tax; states like Delaware, Idaho, Montana, South Dakota, and Wyoming do not have enough power to affect their individuals' welfare through statespecific tax changes, and so on. Therefore, optimal public policy (through individual taxes) in each state is different due to the interactions among states with different sizes.

This paper is connected to the literature investigating the effects of regional taxes on economic activity and interregional individual migration which has found mixed results with regard to the influence of tax policy on location decisions of individuals and the resulting economic activity. ${ }^{1}$ Although it is impossible to mention all relevant studies in this wide literature, the variation in results is due to many factors such as differences in how economic activity or tax policies are measured. Cebula (1979) and Charney (1993) show that many fiscal characteristics have effects on individual utility and thus migration; these include tax and expenditure policies of governments that may change income and the subsequent consumption of individuals. However, most studies are not able to capture the possibility that some individuals are attracted to higher tax burdens if the ensuing government spending is beneficial to them while others are repelled by the higher tax burden as described in the subnational redistribution literature (Dalenberg and Partridge, 1995; Hindriks, 1999, 2001;Razin et al., 2002; Wildasin, 1991, 1994); Knapp et al. (2001) find that higher state income tax liabilities encourage people to stay. The evidence on the effects of regional government revenues (i.e., government size) on regional growth is mixed: for the states of the U.S., while the effect is negative in early 1980s, it has disappeared in early 2000s (see Deskins and Hill, 2010). This paper is able to model that the type of tax is the key in explaining these mixed evidence. There is also another part of the literature that estimates the elasticity of taxable income with respect to the marginal net-of-tax rate (one minus the marginal tax rate; see Feldstein, 1995, Giertz (2007), Long (1999), Bruce et al., 2010); compared to these studies, this

\footnotetext{
${ }^{1}$ Besides many classical papers by Harberger, Mieszkowski, Shoven and Whalley, see Partridge and Rickman (1998) for a discussion of regional public finance computable general equilibrium studies. There is also a wide literature focusing on regional taxes and firm location; see Bartik (1991, 1994), and Wasylenko (1997) for surveys.
} 
paper decomposes the effects of different tax types on wage income and dividend income through a general equilibrium framework.

\section{The Economic Environment}

The economy of a country (or a union) consisting of finite number of regions, individuals, firms (i.e., private sector), and local governments (i.e., public sector) is modeled. The nontechnical summary of the model has already been discussed in the introduction section, so we will not repeat it here. The analysis is made for a typical region, $r$. Each region is specialized in the manufacturing of a unique good; e.g., region $r$ produces good $r$. An individual is denoted by $h$, and total number of individuals in region $r$ is $H_{r}$.

\subsection{Individuals}

A typical individual $h$ in region $r$ maximizes:

$$
U_{r}(h) \equiv \log \left(C_{r}^{C}(h)\right)+\log \left(C_{r}^{L}(h)\right)+\log \left(C_{r}^{P}(h)\right)-\log \left(N_{r}(h)\right)
$$

where $C_{r}^{C}(h)$ is a per capita composite index of consumption goods, $C_{r}^{L}(h)$ is per capita land, $C_{r}^{P}(h)$ is per capita public good in region $r$, and $N_{r}(h)$ is per capita hours of labor supplied. The composite index of consumption goods in region $r$ is further defined as:

$$
C_{r}^{C}(h)=\left(\sum_{i}\left(\theta_{r, i}\right)^{\frac{1}{\eta}}\left(C_{r, i}^{C}(h)\right)^{\frac{\eta-1}{\eta}}\right)^{\frac{\eta}{\eta-1}}
$$

where $C_{r, i}^{C}(h)$ is per capita consumption in region $r$ of good $i$ (produced in region $i$ ), $\eta>1$ is the elasticity of substitution across goods, and finally $\theta_{r, i}$ is a source- and destination-specific taste parameter. The model will allow for migration of individuals across regions, below; hence, one can be skeptical about having region-specific taste parameters, $\theta_{r, i}$ 's in the utility function. In particular, these $\theta_{r, i}$ 's will remain region specific even after migration; i.e., if an individual will move from the New York to Florida, she will encounter new taste parameters that are specific to Florida. In addition to providing simplicity for the analytical solution, this particular assumption is realistic when one compares the living conditions, say, between New York and Florida; e.g., a winter coat (i.e., a variety of coat), say, imported from Georgia and consumed in New York may be replaced by a spring coat (i.e., another variety of coat), say, imported from Wisconsin when 
an individual moves from New York to Florida. Later in the model, $\theta_{r, i}$ 's will be connected to the geographical location of each region through trade costs.

Besides the labor income, each individual also receives $\Gamma(h)$ as profit income, independent of her location of residence. In this context, the individual in region $r$ maximizes Equation 2.1 subject to the following budget constraint:

$$
P_{r}^{L} C_{r}^{L}(h)\left(1+t_{r}^{L}\right)+P_{r}^{C} C_{r}^{C}(h)\left(1+t_{r}^{C}\right) \leq W N_{r}(h)\left(1-t_{r}^{W}\right)+\Gamma(h)\left(1-t_{r}^{D}\right)
$$

where $P_{r}^{L}$ is the price of land in region $r, t_{r}^{L}$ is the tax rate on land (i.e., property tax) in region $r$, $P_{r}^{C}$ is the price of the composite-consumption good in region $r, t_{r}^{C}$ is the sales tax rate in region $r, W$ is hourly nominal wage determined in the national labor market, $t_{r}^{W}$ is the wage-income tax rate in region $r$, and $t_{r}^{D}$ is the dividend-income tax rate in region $r$.

The optimal allocation of any given expenditure yields the following demand function for consumption goods:

$$
C_{r, i}^{C}(h)=\theta_{r, i}\left(\frac{P_{r, i}^{C}}{P_{r}^{C}}\right)^{-\eta} C_{r}^{C}(h)
$$

where $P_{r}^{C} \equiv\left(\sum_{i} \theta_{r, i}\left(P_{r, i}^{C}\right)^{1-\eta}\right)^{\frac{1}{1-\eta}}$ is the cost-of-living index in region $r$. It follows from the equations above that $\sum_{i} P_{r, i}^{C} C_{r, i}(h)=P_{r}^{C} C_{r}^{C}(h)$.

The individual maximizes utility by choosing $C_{r}^{C}(h), C_{r}^{L}(h)$, and $N_{r}(h)$; the amount of public good is determined by the public sector. Therefore, the optimality condition for the individual is given by:

$$
P_{r}^{C} C_{r}^{C}(h)\left(1+t_{r}^{C}\right)=P_{r}^{L} C_{r}^{L}(h)\left(1+t_{r}^{L}\right)=W N_{r}(h)\left(1-t_{r}^{W}\right)
$$

Combining Equations 2.2 and 2.3, an expression for per capita labor supply is obtained:

$$
N_{r}(h)=\frac{\Gamma(h)\left(1-t_{r}^{D}\right)}{W\left(1-t_{r}^{W}\right)}
$$

which depends on region-specific dividend- and wage-income taxes together with the dividend income.

Equation 2.3 implies the following expenditure ratio on consumption goods across regions $r$ and $i$ :

$$
\frac{P_{r}^{C} C_{r}^{C}(h)}{P_{i}^{C} C_{i}^{C}(h)}=\frac{\left(1+t_{i}^{C}\right)\left(1-t_{r}^{D}\right)}{\left(1+t_{r}^{C}\right)\left(1-t_{i}^{D}\right)}
$$


which is basically an expression of region-specific sales and dividend-income taxes. Similarly, the following is the expenditure ratio on land across regions $r$ and $i$ :

$$
\frac{P_{r}^{L} C_{r}^{L}(h)}{P_{i}^{L} C_{i}^{L}(h)}=\frac{\left(1+t_{i}^{L}\right)\left(1-t_{r}^{D}\right)}{\left(1+t_{r}^{L}\right)\left(1-t_{i}^{D}\right)}
$$

\subsection{Production}

There are two types of production in this economy: (i) consumption-good production by the private sector, (ii) public-good production by the public sector.

\subsubsection{Private-Sector Production}

A monopolistically-competitive private-sector production firm in region $r$ produces good $r$ (i.e., perfect specialization) by using labor and intermediate inputs purchased from private-sector production firms in all regions. The production is achieved according to the following constant returns to scale function:

$$
Y_{r}^{C}=A_{r}^{C}\left(L_{r}^{C}\right)^{l}\left(G_{r}^{C}\right)^{g}
$$

where $A_{r}^{C}$ represents good- and region-specific production technology, $L_{r}^{C}$ represents labor, $G_{r}^{C}$ represents a composite intermediate input, and finally, $l$ and $g(=1-l)$ represent the factor shares which are the same across all production firms.

The firm chooses $L_{r}^{C}$ and $G_{r}^{C}$, taking the wage rate and the price of intermediate goods as given. To avoid any double taxation, the production firm does not pay any taxes (remember that the individuals pay dividend taxes instead). Therefore, the cost minimization problem of the firm is as follows:

$$
\begin{gathered}
\min _{L_{r}^{C}, G_{r}^{C}} L_{r}^{C} W+G_{r}^{C} P_{r}^{G} \\
\text { s.t. } Y_{r}^{C}=A_{r}^{C}\left(L_{r}^{C}\right)^{l}\left(G_{r}^{C}\right)^{g}
\end{gathered}
$$

which implies that the marginal cost of producing consumption good $r$ (in region $r$ ) is given by:

$$
M C_{r}^{C}=\left(A_{r}^{C}\right)^{-1}\left(\frac{W}{l}\right)^{l}\left(\frac{P_{r}^{G}}{g}\right)^{g}
$$

where $P_{r}^{G}$ is the intermediate input price index in the production of the consumption good in region $r$. 
Intermediate goods that are used in the production of good $r$ in region $r$ are given by the following index:

$$
G_{r}^{C}=\left(\sum_{i}\left(\theta_{r, i}\right)^{\frac{1}{\eta}}\left(G_{r, i}^{C}\right)^{\frac{\eta-1}{\eta}}\right)^{\frac{\eta}{\eta-1}}
$$

where $G_{r, i}^{G}$ is the intermediate input $i$ (which is imported from region $i$ ). Note that the parameters $\eta$ and $\theta_{r, i}$ are the same as in the utility function of the individuals; although assigning the same parameters as for individuals is not standard, it is necessary to facilitate an analytical solution of the model (as will be clearer, below). The optimality of the firm that produces good $r$ gives the following input demand functions:

$$
G_{r, i}^{C}=\theta_{r, i}\left(\frac{P_{r, i}^{G}}{P_{r}^{G}}\right)^{-\eta} G_{r}^{C}
$$

where $P_{r, i}^{G}$ is the price of the intermediate input imported from region $i$ and $P_{r}^{G} \equiv\left(\sum_{i} \theta_{r, i}\left(P_{r, i}^{G}\right)^{1-\eta}\right)^{\frac{1}{1-\eta}}$.

\subsubsection{Public-Sector Production}

The local government in region $r$ produces a unique public-good by using labor and intermediate inputs purchased from other consumption-good-producing firms in the economy:

$$
Y_{r}^{P}=A_{r}^{P}\left(L_{r}^{P}\right)^{l}\left(G_{r}^{P}\right)^{g}
$$

where $A_{r}^{P}$ represents good- and region-specific public-good-production technology, $L_{r}^{P}$ is labor, $G_{r}^{P}$ represents the composite intermediate input, and finally, $l$ and $g(=1-l)$ again represent the factor shares which are the same across all production firms.

The local government chooses $L_{r}^{P}$ and $G_{r}^{P}$, taking the wage rates and the price of intermediate goods as given. The cost minimization problem of the firm is as follows:

$$
\begin{gathered}
\min _{L_{r}^{P}, G_{r}^{P}} L_{r}^{P} W+G_{r}^{P} P_{r}^{P} \\
\text { s.t. } Y_{r}^{P}=A_{r}^{P}\left(L_{r}^{P}\right)^{l}\left(G_{r}^{P}\right)^{g}
\end{gathered}
$$

which implies that the marginal cost of producing the public good in region $r$ is given by:

$$
M C_{r}^{P}=\left(A_{r}^{P}\right)^{-1}\left(\frac{W}{l}\right)^{l}\left(\frac{P_{r}^{P}}{g}\right)^{g}
$$

where $P_{r}^{P}$ is the intermediate input price index in the production of the public good in region $r$. 
The local government receives all tax revenues together with the land payment itself, since it is assumed to be the owner of all land. Although the simplifying assumption of the government being the owner of all land is not a perfect one, it is to avoid modeling the distribution of ownership of land, as well as issues related to private wealth effects arising from changes in land values associated with changes in public policy. The local government will produce the unique public good under the following condition:

$$
H_{r}\left(\left(1+t_{r}^{L}\right) P_{r}^{L} C_{r}^{L}(h)+t_{r}^{C} P_{r}^{C} C_{r}^{C}(h)+t_{r}^{W} W N_{r}(h)+t_{r}^{D} \Gamma(h)\right)=Y_{r}^{P} M C_{r}^{P}
$$

where $H_{r}$ is the population in region $r$, and the right hand side is due to constant returns to scale (i.e., $g+l=1$ ). Equation 2.12 means that the public-sector in region $r$ will produce public goods until the total cost of production will be equal to the total tax revenue. Notice that the local government is not involved in any game with other local governments and takes the tax rates as given; tax rates are exogenously determined to focus on the policy implications of any tax-rate change.

Intermediate goods that are used in the production of good $r$ in region $r$ are given by the following index:

$$
G_{r}^{P}=\left(\sum_{i}\left(\theta_{r, i}\right)^{\frac{1}{\eta}}\left(G_{r, i}^{P}\right)^{\frac{\eta-1}{\eta}}\right)^{\frac{\eta}{\eta-1}}
$$

where $G_{r, i}^{P}$ is the intermediate input $i$ (which is imported from region $i$ ), and the parameters of $\eta$ and $\theta_{r, i}$ are the same as in the utility function of the individuals for the reasons discussed above. The optimality of the local government results in the following input demand functions:

$$
G_{r, i}^{P}=\theta_{r, i}\left(\frac{P_{r, i}^{P}}{P_{r}^{P}}\right)^{-\eta} G_{r}^{P}
$$

where $P_{r, i}^{P}$ is the price of the intermediate input imported from region $i$ and $P_{r}^{P} \equiv\left(\sum_{i} \theta_{r, i}\left(P_{r, i}^{P}\right)^{1-\eta}\right)^{\frac{1}{1-\eta}}$.

\subsection{Equilibrium}

This section describes the aggregate properties of the model. 


\subsubsection{Consumption-Good}

Individuals of a typical region share the same technology parameters in the production of final-good consumption. Thus, in region $r$, the demand function for good $i$ is given by:

$$
C_{r, i}^{C}=\theta_{r, i}\left(\frac{P_{r, i}^{C}}{P_{r}^{C}}\right)^{-\eta} C_{r}^{C}
$$

where $C_{r, i}^{C}=\sum_{h=1}^{H_{r}} C_{r, i}^{C}(h)=H_{r} C_{r, i}^{C}(h)$ is the total demand for $\operatorname{good} i, C_{r}^{C}=\sum_{h=1}^{H_{r}} C_{r}^{C}(h)=$ $H_{r} C_{r}^{C}(h)$ is the total demand for consumption goods, and $H_{r}$ is the population.

\subsubsection{Land}

Individuals of a typical region equally share the fixed amount of land. Thus, in region $r$, the consumption of land is equal to the fixed supply of it:

$$
\sum_{h=1}^{H_{r}} C_{r}^{L}(h)=H_{r} C_{r}^{L}(h)=C_{r}^{L}=Y_{r}^{L} f_{r}^{L}
$$

where $C_{r}^{L}$ is the total demand of land in region $r, Y_{r}^{L}$ is the fixed amount of land in region $r$ and $f_{r}^{L} \in(0,1)$ is the fraction of land that is supplied (i.e., in use) in region $r$. Considering fraction of land that is supplied is important to capture the economically utilized amount of land in each region; e.g., parts of the states of Nevada, California, Oregon, Idaho and Utah may not be in use due to The Great Basin Desert.

\subsubsection{Public Good}

Individuals of a typical region (say, $r$ ) share the total amount of unique public good:

$$
\sum_{h=1}^{H_{r}} C_{r}^{P}(h)=H_{r} C_{r}^{P}(h)=C_{r}^{P}=Y_{r}^{P}
$$

where $C_{r}^{P}$ is the total demand and $Y_{r}^{P}$ is the total supply in region $r$.

\subsubsection{Labor Market}

The total labor supply of the individuals in all regions $N$ is equal to the sum of the labor demand of (both consumption good and public good production) firms in all regions $L$ :

$$
L=\sum_{r}\left(L_{r}^{C}+L_{r}^{P}\right)=\sum_{r} \sum_{h=1}^{H_{r}} N_{r}(h)=\sum_{r} N_{r}(h) H_{r}=N
$$




\subsubsection{Profits}

The total amount of profit of consumption-good-producing firms in all regions is equally distributed among the individuals in all regions who own an equal share of all firms:

$$
\Gamma(h)=\frac{\sum_{r} \pi_{r}}{H}
$$

where $\pi_{r}$ is the profit of consumption-good-producing firm in region $r$, and $H=\sum_{r} H_{r}$ is the total population in all regions.

\subsubsection{Regional Budget Constraint}

Now, the budget constraint of region $r$ can be written as:

$$
P_{r}^{L} C_{r}^{L}\left(1+t_{r}^{L}\right)+P_{r}^{C} C_{r}^{C}\left(1+t_{r}^{C}\right) \leq W N_{r}\left(1-t_{r}^{W}\right)+\Gamma_{r}\left(1-t_{r}^{D}\right)
$$

where $W N_{r}$ is the total wage income and $\Gamma_{r}=H_{r} \Gamma(h)$ is the total dividend income in region $r$. Together with Equation 2.3, this implies the following expenditure ratio on consumption good across regions $r$ and $i$ :

$$
\frac{P_{r}^{C} C_{r}^{C}}{P_{i}^{C} C_{i}^{C}}=\frac{H_{r}\left(1+t_{i}^{C}\right)\left(\left(1-t_{r}^{D}\right)\right)}{H_{i}\left(1+t_{r}^{C}\right)\left(\left(1-t_{i}^{D}\right)\right)}
$$

the following expenditure ratio on land across regions $r$ and $i$ :

$$
\frac{P_{r}^{L} C_{r}^{L}}{P_{i}^{L} C_{i}^{L}}=\frac{H_{r}\left(1+t_{i}^{L}\right)\left(\left(1-t_{r}^{D}\right)\right)}{H_{i}\left(1+t_{r}^{L}\right)\left(\left(1-t_{i}^{D}\right)\right)}
$$

and the following expenditure ratio between consumption good and land within region $r$ :

$$
\frac{P_{r}^{C} C_{r}^{C}}{P_{r}^{L} C_{r}^{L}}=\frac{1+t_{r}^{L}}{1+t_{r}^{C}}
$$

\subsubsection{Region Specific Utility, Population Levels, and Migration}

In equilibrium, all regions are going to provide the very same level of individual utility; otherwise, individuals are going to migrate to higher-individual-utility regions:

$$
U_{r}(h)=U_{i}(h) \quad \text { for all } i, r
$$




\subsubsection{Market Clearing Condition for the Private Sector}

For each consumption good $r$ (produced in region $r$ ), market clearing condition implies:

$$
Y_{r}^{C}=\sum_{i}\left(1+\tau_{i, r}\right)\left(C_{i, r}^{C}+G_{i, r}^{C}+G_{i, r}^{P}\right)
$$

where $\tau_{i, r}$ represents iceberg transport costs from region $r$ to region $i, C_{i, r}^{C}$ is the final-good consumption demand of region $i$ for good $r$ produced in region $r, G_{i, r}^{C}$ is the intermediate input $r$ used in region $i$ for the production of consumption good $i$, and $G_{i, r}^{P}$ is the intermediate input $r$ used in region $i$ for the production of public good $i$. Equation 2.21 basically says that good $r$ (produced in region $r$ ) is either consumed locally or by other regions, either for final consumption or further production. By using Equations 2.9, 2.14 and 2.14, the market clearing condition for good $r$ can be rewritten as:

$$
\begin{aligned}
Y_{r}^{C} & =\sum_{i}\left(1+\tau_{i, r}\right)\left(\theta_{i, r}\left(\frac{P_{i, r}^{C}}{P_{i}^{C}}\right)^{-\eta} C_{i}^{C}+\theta_{i, r}\left(\frac{P_{i, r}^{G}}{P_{i}^{G}}\right)^{-\eta} G_{i}^{C}+\theta_{i, r}\left(\frac{P_{i, r}^{P}}{P_{i}^{P}}\right)^{-\eta} G_{i}^{P}\right) \\
& =\sum_{i}\left(\left(1+\tau_{i, r}\right) \theta_{i, r}\left(\frac{P_{i, r}}{P_{i}}\right)^{-\eta}\left(C_{i}^{C}+G_{i}^{C}+G_{i}^{P}\right)\right) \\
& =\sum_{i}\left(\frac{\theta_{i, r}}{\left(1+\tau_{i, r}\right)^{\eta-1}}\left(\frac{P_{r, r}}{P_{i}^{C}}\right)^{-\eta}\left(C_{i}^{C}+G_{i}^{C}+G_{i}^{P}\right)\right)
\end{aligned}
$$

where the second equality is due to $P_{i, r}=P_{i, r}^{C}=P_{i, r}^{G}=P_{i, r}^{P}$ (since any traded good is subject to very same trade costs) and thus $P_{i}=P_{i}^{C}=P_{i}^{G}=P_{i}^{P}$ (due to their relation with $P_{i, r}=P_{i, r}^{C}=P_{i, r}^{G}=P_{i, r}^{P}$, respectively, for all $r$ ), while the third equality is due to implication of iceberg transport costs (i.e., $P_{i, r}=P_{r, r}\left(1+\tau_{i, r}\right)$ where $P_{r, r}$ is the factory-gate price of good $r$ in region $\left.r\right)$.

\subsection{Price Setting}

The private-sector firms in each region maximize their profits by using their market power, while the public sector in each region considers its marginal costs to determine the amount of public goods it will produce.

\subsubsection{Private Sector}

In region $r$, the private sector produces good $r$ and faces the following profit maximization problem:

$$
\max _{P_{r, r}} Y_{r}^{C}\left[P_{r, r}-M C_{r}^{C}\right]
$$


subject to Equation 2.21. The first order condition for this problem is as follows:

$$
Y_{r}^{C}\left[1-\frac{\eta}{P_{r, r}}\left(P_{r, r}-M C_{r}^{C}\right)\right]=0
$$

which implies that:

$$
P_{r, r}=\frac{\eta}{\eta-1} M C_{r}^{C}
$$

where $\frac{\eta}{\eta-1}$ represents the gross mark-up.

The profit of the private sector in region $r$ is implied as:

$$
\pi_{r}=Y_{r}^{C}\left[P_{r, r}-M C_{r}^{C}\right]
$$

which further implies that the total amount of profits in all regions to be equally distributed to individuals in all regions is:

$$
\begin{aligned}
\sum_{r} \pi_{r} & =\sum_{r} Y_{r}^{C}\left[P_{r, r}-M C_{r}^{C}\right] \\
& =\frac{1}{\eta-1} \sum_{r} Y_{r}^{C} M C_{r}^{C}
\end{aligned}
$$

Hence, the per-capita dividend payment in all regions is given by:

$$
\begin{aligned}
\Gamma(h) & =\frac{\sum_{r} \pi_{r}}{H} \\
& =\frac{1}{H}\left(\frac{1}{\eta-1}\right) \sum_{r}\left(Y_{r}^{C} M C_{r}^{C}\right)
\end{aligned}
$$

\subsubsection{Public Sector}

The non-profit local governments (i.e., the public sector) do not set prices but consider their costs of production to determine the amount of public good that they will produce (through Equation 2.12):

$$
\begin{aligned}
Y_{r}^{P} & =H_{r}\left(\frac{\left(1+t_{r}^{L}\right) P_{r}^{L} C_{r}^{L}(h)+t_{r}^{C} P_{r}^{C} C_{r}^{C}(h)+t_{r}^{W} W N_{r}(h)+t_{r}^{D} \Gamma(h)}{M C_{r}^{P}}\right) \\
& =\frac{\left(\left(1+t_{r}^{L}\right) P_{r}^{L} C_{r}^{L}+t_{r}^{C} P_{r}^{C} C_{r}^{C}+t_{r}^{W} W N_{r}+t_{r}^{D} \Gamma_{r}\right)}{\left(A_{r}^{P}\right)^{-1}\left(\frac{W}{l}\right)^{l}\left(\frac{P_{r}}{g}\right)^{g}}
\end{aligned}
$$

where Equation 2.11 has been used in the second line. This means that the amount of public good in each region will depend on the tax revenue and the marginal cost of public-good production.

A closed-form solution to the model is given in the Appendix. 


\section{Empirical Analysis}

The empirical analysis consists of two parts: (1) testing the empirical power of the model using the U.S. state-level data covering 50 states and Washington D.C., (2) counterfactuals.

\subsection{Empirical Power}

The empirical power of the model is tested using the U.S. state-level data of (i) bilateral trade across states, (ii) gross state product, (iii) consumption, (iv) government expenditure.

\subsubsection{Parametrization and Estimation Methodology}

The bilateral trade data across the U.S. states are obtained from Commodity Flow Survey (CFS) of the Bureau of Transportation Statistics for the year 2007. CFS depicts both source and destination states for the value of shipments (i.e., exports) that are measured at the source. ${ }^{2}$ To make the connection between CFS and the model, we use the overall value of shipments. According to the model of this paper, the total value of trade from region $i$ to region $r$ at the source (i.e., region $i$ ) is given by the following expression:

$$
P_{i i} X_{r i}=P_{i i}\left(C_{r, i}^{C}+G_{r, i}^{C}+G_{r, i}^{P}\right)
$$

where $X_{r i}=C_{r, i}^{C}+G_{r, i}^{C}+G_{r, i}^{P}$ represents the total quantity of exports, and the closed form solutions of $P_{i i}, C_{r, i}^{C}, G_{r, i}^{C}$, and $G_{r, i}^{P}$, are given by Equations 6.6, 6.17,6.21, and 6.24, respectively. Note that when $r=i$, the expression above represents the total value of trade within the region; the data for intra-regional trade are also available in CFS. To test the model, the left hand side of Equation 3.1 (i.e., the trade data set coming from CFS) is compared with the right hand side of it (i.e., the model).

The gross state product data for each U.S. state are obtained from Bureau of Economic Analysis (BEA) for the year 2007. According to the model of this paper, the gross domestic product in

\footnotetext{
${ }^{2}$ In CFS, shipments traversing the U.S. from a foreign location to another foreign location (e.g., from Canada to Mexico) are not included. Shipments that are shipped through a foreign territory with both the origin and destination in the U.S. are included in the CFS data; The mileages calculated for these shipments exclude the international segments (e.g., shipments from New York to Michigan through Canada do not include any mileages for Canada).
} 
region $r$ (calculated by the value-added approach) is given by the following expression:

$$
G S P_{r}=P_{r r} Y_{r}^{C}+M C_{r}^{P} Y_{r}^{P}-\left(\sum_{i \neq r} P_{r, i}^{C} G_{r, i}^{C}\right)-\left(\sum_{i} P_{r, i}^{P} G_{r, i}^{P}\right)
$$

where the closed form solutions of $P_{r r}, Y_{r}^{C}, M C_{r}^{P}, Y_{r}^{P}, P_{r, i}^{C}, G_{r, i}^{C}, P_{r, i}^{P}$, and $G_{r, i}^{P}$ are given by Equations $6.6,6.18,6.14,6.19,6.7,6.21,6.8$, and 6.24 respectively. To test the model, the left hand side of Equation 3.2 (i.e., the gross state product data set coming from BEA) will be compared with the right hand side of it (i.e., the model), below.

The value of consumption data for each U.S. state are the state-level retail sales obtained from Bureau of Economic Analysis for the year 2007. According to the model of this paper, the value of consumption in region $r$ is given by $P_{r}^{C} C_{r}^{C}$ where the closed form solutions for $P_{r}^{C}$ and $C_{r}^{C}$ are given by Equations 6.9, 6.10, and 6.12. To test the model, the retail sales data will be compared with $P_{r}^{C} C_{r}^{C}$ (i.e., the model), below.

The value of government expenditure for each U.S. state are obtained from Bureau of Economic Analysis for the year 2007. ${ }^{3}$ According to the model of this paper, the value of government expenditure in region $r$ is given by $Y_{r}^{P} M C_{r}^{P}$ where the closed form solutions for $Y_{r}^{P}$ and $M C_{r}^{P}$ are given by Equations 6.19 and 6.14. To test the model, the government expenditure data will be compared with $Y_{r}^{P} M C_{r}^{P}$ (i.e., the model), below.

Since the closed-form solution of all region-specific endogenous variables are given in terms of region-specific exogenous variables and parameters (i.e., tax rates, technology levels of both private and public sectors, iceberg trade costs, land sizes, the fraction of land that is supplied, total population in all regions, and the elasticity of substitution across goods), we have to determine these before the empirical test.

The tax rates are obtained from Tax Foundation for the year 2007. For each state, in the data, when relevant, any tax rate is calculated as the sum of federal, social security, medicare, and state taxes; the only exception are the state-level property tax rates which are calculated by using the local tax paid for the median-value house in each state. ${ }^{4}$ Since most taxes are progressive (i.e.,

\footnotetext{
${ }^{3}$ Government expenditure at the state level is the sum of (i) Federal Government, (ii) State and Local Governments, (iii) Federal Reserve Banks, (iv) Credit Intermediation and Related Services, (v) Federal Civilian, and (vi) Federal Military.

${ }^{4}$ The tax paid for the median-value house in each state has been obtained by dividing the median property taxes paid on houses by the annual mortgage payment of the median-value house on a 30-year loan where the mortgage rate has been taken as $6.2 \%$ for the year 2007 .
} 
the tax rate increases as the taxable base amount increases), we use the national average income published by the Social Security Administration for the year 2007 as the taxable base amount. The tax rates in each state are given in Figure 1 on the U.S. map (after excluding outliers of Alaska, Washington D.C., and Hawaii). As is evident, although wage-income, dividend-income and sales taxes are somehow close to each other across states with a range of around 10\%, the property taxes are more dispersed where the west and the southeast of the U.S. has lower rates.

The private sector technology levels are obtained by multiplying each side of Equation 5.14 by the ratio of source prices across regions $a$ and $b$ :

$$
\begin{aligned}
\frac{P_{a, a} Y_{a}^{C}}{P_{b, b} Y_{b}^{C}} & =\left(\frac{P_{a, a}}{P_{b, b}}\right)^{1-\eta} \\
& =\left(\frac{A_{a}^{C}}{A_{b}^{C}}\right)^{\eta-1}
\end{aligned}
$$

where Equations 5.2 and 5.3 have been used in the second line. The left hand side of Equation 3.3 is obtained from CFS (i.e., the trade data above) by using the value of total exports in each state (including trade within each state) as a measure of output. After setting the private-sector technology level in California equal to one (i.e., $A_{C A L I F O R N I A}^{C}=1$ ), $A_{a}^{C}$ 's for all $a$ are identified when the elasticity of substitution $\eta$ is known. ${ }^{5}$

The public sector technology levels are calculated using Equation 5.27 where the tax rates are as described above. After setting the public-sector technology level in California equal to one (i.e., $\left.A_{C A L I F O R N I A}^{P}=1\right), A_{a}^{P}$ 's for all $a$ are identified. ${ }^{6}$ The public-sector technology level of each state is provided on the U.S. map in Figure 1 (after excluding outliers of Alaska, Washington D.C., and Hawaii); as is evident, the northeast and the middle of the country has higher levels compared to other regions.

The iceberg trade costs between regions $r$ and $i$ are proxied using the following expression that is generally used in the literature:

$$
\left(1+\tau_{i, r}\right)=\left(D_{i, r}\right)^{\delta}
$$

where $D_{i, r}$ is the distance from region $r$ to region $i$, and $\delta$ represents the elasticity of distance. The distances used are the actual (average) distances of shipment in miles provided by CFS (i.e.,

\footnotetext{
${ }^{5}$ There is no scale effect of the private-sector technology levels on the empirical results, because we use the values rather than quantities in the empirical analysis.

${ }^{6}$ There is no scale effect of the public-sector technology levels on the empirical results, because we use the values rather than quantities in the empirical analysis.
} 
the trade data above); these include the distance of shipment within each state. The elasticity of distance $\delta$ is going to be selected to match the trade data, as will be clearer below.

The total land size/area of each state in square miles (e.g., $Y_{r}^{L}$ for region $r$ in the model) and population of each state (e.g., $H_{r}$ for region $r$ in the model) is obtained from the U.S. Census Bureau for the year 2007. The fraction of land that is supplied in each state is calculated using Equation 5.11 after setting the fraction equal to one in California (i.e., $f_{C A L I F O R N I A}^{L}=1$ ). Notice that the population of each state (which is an endogenous variable) is used only to calculate $f_{r}^{L}$ 's for all $r$; in the empirical analysis, only the total population of all states (i.e., the population of the U.S.) and $f_{r}^{L}$ 's are used. Both population levels and the fraction of land/area supplied in each state are provided in Figure 1 (after excluding outliers of Alaska, Washington D.C., and Hawaii; e.g., $f_{D C}^{L}=51.85, f_{A L A S K A}^{L}=0.004$, ). The most appealing part is that Rhode Island, New Jersey, Massachusetts, Maryland, and Delaware all have $f^{L}$ values higher than 2 (i.e., the fraction of land that they supply are at least twice what California supplies), while North Dakota, Montana, Wyoming, and South Dakota all have $f^{L}$ values lower than 0.05 (i.e., the fraction of land that they supply are at least 20 times lower than what California supplies). Since the model of this paper does not focus on the land used in production, these figures of $f^{L}$ reflect the fraction of land consumed by the individuals as properties in each state; hence, we control for the land used in production explicitly.

The only unknown parameters left that are necessary to simulate the model are the elasticity of substitution across goods $\eta$ and the elasticity of distance $\delta$. Since these are mostly traderelated parameters, to estimate them, given the data and parametrization above, the data vector of bilateral trade across states is compared with the corresponding vector obtained by the model subject to $\eta$ and $\delta$ values; i.e., given the parametrization so far, $\eta$ and $\delta$ are selected to match the trade data best through a global grid search. This is the only estimation achieved in this paper.

\subsubsection{Estimation Results}

The estimation result in $\eta=3.0$ and $\delta=0.38$. In the literature, in terms of the elasticity of substitution across goods $\eta$, Hummel's (2001) estimates range between 4.79 and 8.26; the estimates of Head and Ries (2001) range between 7.9 and 11.4; the estimate of Baier and Bergstrand (2001) is about 6.4; Harrigan's (1996) estimates range from 5 to 10; Feenstra's (1994) estimates range from 3 to 8.4; the estimate by Eaton and Kortum (2002) is about 9.28; the estimates by Romalis (2007) 
range between 6.2 and 10.9; the (mean) estimates of Broda and Weinstein (2006) range between 4 and 17.3. Therefore, the estimate of this paper in terms of the elasticity of substitution across goods lies in the lower part of the estimation range in the literature. In the literature, the elasticity of distance $\delta$ estimates are about 0.3 (see Hummels, 2001; Limao and Venables, 2001; Anderson and van Wincoop, 2004); hence, the elasticity of distance estimate of this paper is slightly higher compared to the literature.

After knowing for the elasticity of substitution $\eta=3$, we can now also depict the private-sector technology level in each state (i.e., $A_{r}^{C}$ for all $r$ ); the descriptive analysis is given in Figure 1 (after excluding outliers of Alaska, Washington D.C., and Hawaii). As is evident, California and Texas have the highest level of private-sector technology (i.e., $A_{C A L I F O R N I A}^{C}=1, A_{T E X A S}^{C}=0.99$ ), while Vermont, Rhode Island, Wyoming, and South Dakota have technology levels below 0.25.

\subsubsection{Empirical Power of the Model}

Although $\eta=3.0$ and $\delta=0.38$ match the trade data best, it does not mean that the model completely explains the data. In order to test the empirical power of model under the parametrization of $\eta=3.0$ and $\delta=0.38$, we check the correlation between the model implications and the data for trade, GSP, consumption, and government expenditure as they have been described above. The results given in Figure 2 are very encouraging: The correlation between the model and the data is 0.96 for trade ${ }^{7}, 0.98$ for GSP (where both the data and the model have been set to one for California), 0.99 for consumption (where both the data and the model have been set to one for California), and 0.98 for government expenditure (where both the data and the model have been set to one for California).

\subsection{Counterfactuals at the National Level}

The model of this paper is rich enough to consider counterfactuals at the national level (e.g., the effects of a nationwide change in tax rates) and the state level (e.g., the effects of a statelevel change in tax rates). We will first focus on the national-level counterfactuals, since they have important federal public-policy implications for the U.S. economy. Given the tax rates in 2007, the counterfactual analysis consists of investigating the effects of nationwide changes in wage-income

\footnotetext{
${ }^{7}$ Although the correlation coefficient reflects the correlation between the levels, the figure for trade has log variables in its axes for presentational purposes.
} 
taxes, dividend-income taxes, property taxes, and sales taxes on the macroeconomic variables at the national and state levels. To achieve a welfare analysis, the macroeconomic variables that we focus on are the individual welfare measured by the individual utility function and the components of the individual utility function, namely per capita consumption good $C_{r}^{C}(h)$, per capita land $C_{r}^{L}(h)$, per capita public good $C_{r}^{P}(h)$, and per capita hours of work $N_{r}(h)$.

The nationwide changes in tax rates are defined as equal percentage increases in the tax rates in all states. The vertical axes in Figure 3 show the elasticities of variables with respect to tax rates (where the elasticity is defined as usual: the effect of a 1\% change in tax rates on national variables in percentage terms), and the horizontal axes show the percentage change in tax rates. Although the individual utilities are equalized in the model by migration, each component of the individual utility function may take different values in each state; hence, we will show the average (across states) responses of $C_{r}^{C}(h), C_{r}^{L}(h), C_{r}^{P}(h)$, and $N_{r}(h)$. As is evident in the top left part of Figure 3, an increase in dividend-income tax or property tax at the national level increases individual welfare, and an increase in wage-income tax or sales tax decreases individual welfare, ceteris paribus. The highest welfare increase is due to an increase in dividend-income tax with an elasticity of about 5.25, and the highest welfare reduction is due to an increase in wage-income tax with an elasticity of about -3.77 ; changes in sales or property taxes have almost no effects on individual welfare. Elasticities through dividend- and wage-income taxes need further investigation, since they are significantly high.

The rest of Figure 3 can help us understand the sources of these high elasticities. For instance, the main sources of the high elasticity of individual welfare with respect to dividend-income tax are through the changes in per capita consumption good and per capita public good; according to the bottom right part of Figure 3, the fall in the price level seems to be effective on these changes. According to the model, the most effective chain of logic is as follows: (i) The private-sector firms produce more output to cover for increased dividend-income taxes, because the after-tax dividendincome must remain the same in nominal wage terms (i.e., the numeraire) due to individual optimality condition (caused by log-additive utility function). (ii) Raise in the private-sector production lowers the price level and hence intermediate input costs for further production in the private sector. (iii) Reduced intermediate input costs lead all firms to increase the intermediateinput share $g$ in production which increases the demand for the goods produced by private-sector firms; hence the production in the private sector increases even more and the price level (in 
nominal wage terms) falls such that the per capita consumption of the consumption good increases. (iv) Reduced intermediate input prices, together with higher tax revenues, lead to higher public sector production and hence higher per capita public good consumption. (v) The increases in per capita consumption good and per capita public good lead to higher individual welfare. The main ingredient in this chain of logic is the existence of intermediate input trade in the model; i.e., the individual welfare would not be positively affected by the changes in dividend-income taxes in the absence of intermediate input trade. To show this formally, consider the case with no intermediate input trade by setting the share of intermediate input share in the production of both private and public sector $g$ to 0; i.e., make labor the only input. In such a case, the price level would depend only on the nationwide wage rate, which would remain the same after a possible change in taxes, because it is the numeraire. With a constant price level and an increased dividend-income tax, (i) the per capita consumption of the consumption good would fall, (ii) individuals would supply fewer labor to compensate for the reduction in per capita consumption, (iii) reduction in labor supply would lead to fewer production in both public and private sectors, (iv) the fall in the public-sector production due to lower labor supply would be higher than the raise in the public-sector production due to higher tax revenue, because the profit of private-sector firms (hence, the tax revenue) would further go down due to lower labor supply. The details of the special case with $g=0$ are given in Figure 4 where the changes in $C_{r}^{C}(h), C_{r}^{L}(h), C_{r}^{P}(h), N_{r}(h)$ and the overall utility due to a change in dividend-income tax are depicted. Figure 4 supports the claim of having negative effects of dividend-income tax increases on individual welfare in the absence of intermediate input trade. Hence, intermediate inputs play an important role in determining the welfare implications of tax rate changes.

A similar analysis can be achieved for the wage-income tax as well. According to Figure 3, the main sources of the high elasticity of individual welfare with respect to wage-income tax are through the changes in per capita consumption good and per capita hours of work; this time, the increase in the price level seems to be the reason for such changes. According to the model, the most effective chain of logic this time is as follows: (i) Individuals work more to compensate for lower after-tax wage income. (ii) Higher labor supply leads to an increase in the labor input share $l$ in the production of both private and public sectors. (iii) Increased labor input share leads to lower intermediate input trade and hence reduces private-sector production. (iv) Lower private-sector production, together with higher prices, lead to lower per capita consumption of the consumption 
good. (v) Lower per capita consumption, together with higher per capita hours of work, leads to lower individual welfare. Again, this particular result is due to the existence of intermediate input trade. To see why, consider again the case with no intermediate input trade, i.e., $g=0$. In such a case, the price level would remain the same after the change in wage-income tax rate, as above. With a constant price level and an increased wage-income tax, (i) individuals would work more to compensate for lower after-tax wage income, (ii) higher labor supply would lead to an increase in private-sector production until the reduction in after-tax wage income is compensated by higher per capita consumption of the consumption good, (iii) however, high labor supply would also imply higher production in the public sector that uses only labor as the factor of production now, (iv) higher public-sector production means higher per capita public-good consumption, (v) the fall in individual welfare due to higher labor supply would be higher than the raise in individual welfare due to higher per capita public good, because we have a log-additive utility function with equal shares on per capita public good and hours of work with opposite signs. The details of the special case with $g=0$ are again given in Figure 4 where the changes in $C_{r}^{C}(h), C_{r}^{L}(h), C_{r}^{P}(h), N_{r}(h)$ and the overall utility due to a change in wage-income tax are depicted. Figure 4 supports the view that an increase in wage-income tax in the absence of intermediate input trade leads to lower individual welfare. Hence, once again, intermediate inputs play an important role in determining the welfare implications of tax rate changes.

Although the effects of sales and property taxes on individual welfare are minor, they can still be investigated by Figure 3. For instance, when sales taxes increase, (i) individuals start consuming fewer private-sector consumption goods, (ii) the fall in demand for consumption goods leads to lower prices, (iii) lower prices lead to higher public-sector production through lower intermediate input prices, (iv) per capita consumption of the consumption good falls but per capita consumption of the public good increases; hence, the overall effect on individual welfare is minimal. Similarly, when property taxes increase, (i) individuals start consuming fewer land, (ii) individuals work more to compensate for lower land, (iii) production increases in both private and public sectors, (iv) the overall effect on the individual welfare is again minimal.

Figure 3 depicts the effects of national tax rate changes on the national (aggregate) variables, but it does not provide any information regarding how each state is affected by such policies. The left panels of Tables 1-4 bridge this gap by providing the state-level elasticities of endogenous variables with respect to nationwide tax rates. The geographical presentation of Tables 1-4 are 
provided on the U.S. maps in Figures 5-8 (after excluding outliers of Alaska, Washington D.C., and Hawaii).

The left panel of Table 1 and Figure 5 depict the elasticities of state-level variables with respect to nationwide wage-income tax rates. As is evident, although the individual-level utilities are equalized across states, there is evidence for heterogeneity in the components of the individual utility in terms of state-level responses to the changes in tax rates.

\subsection{Counterfactuals at the State Level}

We will now focus on the state-level (local) counterfactuals (i.e., the effect of a state-level change in tax rates), since they have important public-policy implications for each state. Given the tax rates in 2007, the counterfactual analysis consists of investigating the effects of a state-level change in wage-income taxes, dividend-income taxes, property taxes, and sales taxes on the macroeconomic variables at the state-level (where we skip the results on national-level variables which are less significant when state-level changes in tax rates are considered).

The state-level changes in tax rates are defined as percentage changes in the tax rates in only one state. The right panels of Tables 1-4 and Figure 9-12 (after excluding outliers of Alaska, Washington D.C., and Hawaii) show the elasticities of state-level variables with respect to tax rates in the very same states, ceteris paribus (i.e., the percentage change in state-level variables with respect to one percent increase in tax rates; the elasticities are almost identical when calculated with respect to one percent decrease in tax rates).

The right panel of Table 1 and Figure 9 depict the elasticities of state-level variables with respect to their-own-state-level wage-income tax rates. As is evident, individual welfare in all states are affected negatively by an increase in state-level wage-income tax, and there is significant heterogeneity across states in terms of magnitudes. For instance, California has an elasticity of about -0.43 and Wyoming of about -0.01 . When we investigate the components of the individual utility function, the difference between California and Wyoming seems to be due to the differences in the responses of per capita consumption of the consumption good in these two states; i.e., per capita consumption in California falls by 0.21 percent and it remains almost the same in Wyoming. The chain of logic through the model of this paper is pretty much the same as in the counterfactuals at the national level, above; one important difference here is that tax rate changes in one state cannot be as effective as a nationwide tax rate change. In particular, due 
to the economic interactions between states (especially the national labor market), each state is affected according to its population level; this is why the most populated state, California, is affected most, and the least populated state, Wyoming is affected least. Similarly, the right panels of Table 2-4 and Figures 10-12 depict the elasticities of state-level variables with respect to theirown-state-level dividend-income tax rates, property taxes, and sales taxes, respectively; for all tax types, although the chains of logic are the same as in the counterfactuals at the national level, the differences in elasticities across states are again mostly due to the population level of each state. Many state-level public-policy implications follow; e.g., California would benefit significantly from an increase in any tax type but wage-income tax; states like Delaware, Idaho, Montana, South Dakota, and Wyoming simply do not have enough power to affect their individuals' welfare through state-specific tax changes, and so on. Therefore, optimal public policy (through individual taxes) in each state is different due to the interactions among states with different sizes.

\section{Concluding Remarks and Discussion}

Regional taxes are important public-policy tools that have implications on macroeconomic variables at both regional and national levels. This paper has introduced a general equilibrium regional trade model with an analytical solution to investigate the implications of regional taxes that individuals pay. The model is rich enough to consider a private sector, a public sector, individual migration, intermediate inputs trade, and final goods trade across regions. State-level evidence from the U.S. support the model almost perfectly. The analytical solution of the model makes counterfactuals tractable, which suggest for the U.S. economy that a nationwide increase in the state-level dividendincome tax rates would be the best option to expand the private sector, public sector, and, most importantly, the individual welfare in all states; a nationwide increase in the state-level wageincome tax rates would hurt the economy in all states; property and sales taxes have fewer effects on the U.S. economy. We show that these results are mainly driven by intermediate input trade between private and public sectors. The empirical results also depict the elasticities of nationaland state-level macroeconomic variables with respect to both nationwide and state-specific tax rates; e.g. California is positively (respectively, negatively) affected most, among all states, by changes in its dividend-income, property, and sales taxes (respectively, wage-income tax), while Wyoming is one of the least affected by any of its tax rate change. Since the data of this paper is from the year 2007, these results correspond to important policy suggestions for local governments, 
especially after the slowdown in the national economy that has started through the end of the year 2007.

This paper has focused on the elasticities of macroeconomic variables with respect to regional taxes, which are accepted as given, to investigate regional-policy implications. As Kehoe (2003) puts perfectly in the context of technology levels, the point is not that one should want to take the regional taxes as exogenous; in fact, the point is exactly the opposite: if a model with regional taxes treated as exogenous accounts for most regional and macroeconomic fluctuations/trends, then it will be clear that it is changes in regional taxes that needs to be explained; this paper has followed this strategy. For sure, such regional taxes can be endogenized through introducing tax competition across regional governments (among many others, see literature surveys of Wilson, 1999; Paty, 2008); this would generate richer comparative statics.

The results of this paper should be qualified with respect to the structural model that does not allow corporate taxes or firms to use land as a factor of production; this is mostly to keep the model as simple as possible and to focus on regional taxes that individuals pay rather than regional corporate taxes, since the latter has been investigated extensively in the literature (see Morgan et al., 1989; Buss, 2001). Nevertheless, the model has been set in such a way that explicitly controls for possible effects of land-using firms in the data (i.e., through the fraction of land supplied to individuals in each state). Other than using land as a factor of production

and considering corporate taxes, the model and results are subject to further improvement also through introducing an industry-level model, extending to model to examine short-term dynamics, considering factor endowments other than land, considering tax exemptions, introducing migration costs (to investigate same-sign problem), considering tax capitalizations, introducing excise taxes, and/or differentiating between local and federal governments (e.g., vertical externalities); these would also generate richer comparative statics.

\section{References}

[1] Anderson, J.E., and Wincoop, E.V., (2004), "Trade Costs", Journal of Economic Literature, 42: 691-751.

[2] Baier, SL. and Bergstrand, JH., (2001). "The growth of world trade: tariffs, transport costs, and income similarity," Journal of International Economics, 53(1): 1-27 
[3] Bartik TJ, (1991) "Who benefits from state and local economic development policies?" Upjohn Institute, Kalamazoo

[4] Bartik TJ, (1994) "Jobs, productivity, and local economic development: what implications does economic research have for the role of government?" Nationall Tax Journal 47(4):847-861

[5] Broda, C., and Weinstein, D.E., (2006), "Globalization and the Gains from Variety", Quarterly Journal of Economics, 121(2): 541-585.

[6] Bruce, DJ, Fox WF, and Yang, Z., (2010) "Base Mobility and State Personal Income Taxes," National Tax Journal, Forthcoming.

[7] Buss, TF (2001), "The Effect of State Tax Incentives on Economic Growth and Firm Location Decisions: An Overview of the Literature," Economic Development Quarterly, 15(1): 90-105

[8] Cebula R (1979) "Survey of the literature on the migration impact of state and local government policies." Public Finance 34(1):69-83

[9] Cebula J, Vedder R (1973) "A note on migration, economic opportunity, and the quality of life.' Journal of Regional Science 13:205-211

[10] Dalenberg, D.R. and Partridge, M.D., (1995), "The Effects of Taxes, Expenditures, and Public Infrastructure on Metropolitan Area Employment," Journal of Regional Science, 35(4), 617 640

[11] Deskins J and Hill B, (2010). "State taxes and economic growth revisited: have distortions changed?," The Annals of Regional Science, 44(2): 331-348

[12] Eaton, J., and Kortum, S., (2002), "Technology, Geography and Trade", Econometrica, 70(5): 1741-1779.

[13] Feenstra, R. (1994), "New Product Varieties and the Measurement of International Prices," American Economic Review, 84(1), 157-177

[14] Feldstein, M. (1995). "Behavioral Response to Tax Rates: Evidence from the Tax Reform Act of 1986." American Economic Review 85(2): 170-174.

[15] Giertz, SH. (2007). "The Elasticity of Taxable Income Over the 1980s and 1990s" National Tax Journal, 60(4): 743-768. 
[16] Greenwood MJ (1985) "Human migration: theory, models and empirical studies. Journal of Regional Science 25:521-544.

[17] Greenwood MJ (1997) "Internal migration in developed countries. Handbook of Population Family Economics 1B:647-720

[18] Harrigan, J., (1996), "Openness to Trade in Manufactures in the OECD", Journal of International Economics, 40: 23-39.

[19] Head, K. and Ries, J., (2001), "Increasing Returns versus National Product Differentiation as an Explanation for the Pattern of U.S.-Canada Trade", American Economic Review, 91(4): 858-876.

[20] Hicks, John R. 1932. The Theory of Wages. London: Macmillan Press.

[21] Hindriks J (1999) The consequences of labour mobility for redistribution: tax vs. transfer competition. Journal of Public Economics 74:215-234.

[22] Hindriks J (2001) Mobility and redistributive politics. Journal of Public Economics Theory 3:95-120.

[23] Hsing Yu (1995/1996) A note on interstate migration and tax burdens: new evidence. Journal of Applied Business Research 12(1):12-14

[24] Hummels, D., (2001), "Toward a Geography of Trade Costs", mimeo.

[25] Johnson, N, Collins, C, and Singham, A., (2010), "State Tax Changes in Response to Recession" Center on Budget and Policy Priorities.

[26] Kehoe, T.J., (2003), "An Evaluation of the Performance of Applied General Equilibrium Models of the Impact of NAFTA", mimeo.

[27] Limao, N and Venables, AJ, (2001) "Infrastructure, Geographical Disadvantage, Transport Costs, and Trade", The World Bank Economic Review, 15:(3), 451-479

[28] Long, JE. (1999). "The Impact of Marginal Tax Rates on Taxable Income: Evidence from State Income Tax Differentials." Southern Economic Journal 65(4): 855-869. 
[29] Morgan, W., J. Mutti, and M. Partridge. 1989. A regional general equilibrium model of the United States: Tax exects on factor movements and regional production. The Review of Economics and Statistics 71: 626-635.

[30] Orszag, P and Stiglitz, J, (2001), "Budget Cuts vs. Tax Increases at the State Level: Is one more Counter-Productive than the Other?" Center on Budget and Policy Priorities.

[31] Partridge, Mark D. and Dan S. Rickman, 1998. "Regional Computable General Equilibrium Modeling: A Survey and Critical Appraisal," International Regional Science Review 21, 205248.

[32] Paty, S, (2008), "Tax Competition and New Economic Geography," Urban Public Economics Review, 8: 69-83.

[33] Razin A, Sadka E, Swagel P (2002) "Tax burden and migration: a political economy theory and evidence." Journal of Public Economics 85:167-190.

[34] Romalis, J., (2007), "NAFTA's and CUSFTA's Impact on International Trade", The Review of Economics and Statistics, 89(3): 416-435

[35] Sjaastad, Larry A. 1962. "The Costs and Returns of Human Migration," Journal of Political Economy, 70, 80-93.

[36] Todaro, M. 1969. "A Model of Labor Migration and Urban Development in Less Developed Countries," American Economic Review, 59, 138-148.

[37] Wasylenko,Michael (1997) "Taxation and economic development: the state of the economic literature." New Engl Econ Rev March/April:37-52

[38] Wildasin DE (1991) "Income redistribution in a common labor market." American Economic Review 81:757-774

[39] Wildasin DE (1994) "Income redistribution and migration." Canadian Journal of Economics $27: 637-656$.

[40] Wilson, J. (1999), "Theories of Tax Competition", National Tax Journal, 52: 269-304. 


\section{Appendix A: Analytical Solution and Implications}

This section presents the closed-form solution of the model. By using Equations 2.8 and 2.23, the price of consumption good $r$ at the factory gate in region $r$ can be written as:

$$
P_{r, r}=\frac{\eta}{\eta-1}\left(A_{r}^{C}\right)^{-1}\left(\frac{W}{l}\right)^{l}\left(\frac{P_{r}}{g}\right)^{g}
$$

Equation 5.1 implies that the ratio of factory gate price of goods $a$ and $b$ is given by:

$$
\frac{P_{a, a}}{P_{b, b}}=\frac{A_{b}^{C}\left(P_{a}\right)^{g}}{A_{a}^{C}\left(P_{b}\right)^{g}}
$$

which is inversely related to the variety (region) specific technology levels.

To keep the model tractable, the region-specific parameters $\theta_{r, i}$ 's are assumed to be functions of transport costs; i.e., $\theta_{r, i}=\left(1+\tau_{r, i}\right)^{(\eta-1)}$. Together with $P_{r, i}=P_{i, i}\left(1+\tau_{r, i}\right)$, this implies that

$$
\begin{aligned}
P_{r} & \equiv\left(\sum_{i} \theta_{r, i}\left(P_{r, i}\right)^{1-\eta}\right)^{\frac{1}{1-\eta}} \\
& =\left(\sum_{i}\left(P_{i, i}\right)^{1-\eta}\right)^{\frac{1}{1-\eta}}
\end{aligned}
$$

which means that

$$
P_{r}^{C}=P_{r}^{G}=P_{r}^{P}=P_{r}=P_{i}=P \quad \text { for all } r \text { and } i
$$

Combined with Equation 5.1, this implies that

$$
P=\left(\frac{1}{A^{C}}\left(\frac{\eta}{\eta-1}\left(\frac{W}{l}\right)^{l}\left(\frac{1}{g}\right)^{g}\right)\right)^{\frac{1}{1-g}}
$$

where $A^{C}=\left(\sum_{i}\left(A_{i}^{C}\right)^{\eta-1}\right)^{\frac{1}{\eta-1}}$ is an index of technology in the production of consumption good in the country (consisting of all regions).

Therefore, the marginal cost of consumption-good production (Equation 2.8) can be rewritten as:

$$
\begin{aligned}
M C_{r}^{C} & =\left(A_{r}^{C}\right)^{-1}\left(\frac{W}{l}\right)^{l}\left(\frac{P_{r}^{G}}{g}\right)^{g} \\
& =\left(\frac{W}{A_{r}^{C} l}\right)\left(\frac{1}{A^{C}} \frac{1}{g} \frac{\eta}{\eta-1}\right)^{\frac{g}{1-g}}
\end{aligned}
$$

Similarly, the marginal cost of public-good production (Equation 2.11) can be rewritten as:

$$
\begin{aligned}
M C_{r}^{P} & =\left(A_{r}^{P}\right)^{-1}\left(\frac{W}{l}\right)^{l}\left(\frac{P_{r}^{P}}{g}\right)^{g} \\
& =\left(\frac{W}{A_{r}^{P} l}\right)\left(\frac{1}{A^{C}} \frac{1}{g} \frac{\eta}{\eta-1}\right)^{\frac{g}{1-g}}
\end{aligned}
$$


This implies that the total amount of profits in all regions is:

$$
\begin{aligned}
\Gamma & =\sum_{r} \pi_{r} \\
& =\sum_{r} Y_{r}^{C}\left[P_{r, r}-M C_{r}^{C}\right] \\
& =\frac{1}{\eta-1} \sum_{r} Y_{r}^{C} M C_{r}^{C} \\
& =\left(\frac{1}{\eta-1}\right)\left(\frac{W}{l}\right)\left(\frac{1}{A^{C}} \frac{1}{g} \frac{\eta}{\eta-1}\right)^{\frac{g}{1-g}} \sum_{r} \frac{Y_{r}^{C}}{A_{r}^{C}}
\end{aligned}
$$

Hence, the per-capita dividend payment is

$$
\begin{aligned}
\Gamma(h) & =\frac{\Gamma}{H} \\
& =\frac{1}{H} \frac{1}{\eta-1}\left(\frac{1}{A^{C}} \frac{1}{g} \frac{\eta}{\eta-1}\right)^{\frac{g}{1-g}}\left(\frac{W}{l}\right)^{\frac{l}{1-g}} \sum_{r} \frac{Y_{r}^{C}}{A_{r}^{C}}
\end{aligned}
$$

Combining Equation 2.3, 2.4 and 2.15, one can obtain an expression for per capita consumption in region $r$ :

$$
\begin{aligned}
C_{r}^{C}(h) & =\frac{\Gamma(h)\left(1-t_{r}^{D}\right)}{P_{r}^{C}\left(1+t_{r}^{C}\right)} \\
& =\frac{P_{r}^{L} Y_{r}^{L} f_{r}^{L}\left(1+t_{r}^{L}\right)}{W H_{r}\left(1+t_{r}^{C}\right)\left(\left(\frac{1}{A^{C}} \frac{\eta}{\eta-1}\right)^{\frac{1}{1-g}}\left(\frac{1}{l}\right)\left(\frac{1}{g}\right)^{\frac{g}{1-g}}\right)}
\end{aligned}
$$

Combining the first line of this with Equations 5.3, 5.4 and 5.5 results in:

$$
C_{r}^{C}(h)=\left(\frac{\left(1-t_{r}^{D}\right) A^{C}}{H\left(1+t_{r}^{C}\right) \eta}\right) \sum_{r} \frac{Y_{r}^{C}}{A_{r}^{C}}
$$

which implies through using the second line of Equation 5.6 that

$$
\sum_{r} \frac{Y_{r}^{C}}{A_{r}^{C}}=\frac{H P_{r}^{L} Y_{r}^{L} f_{r}^{L}\left(1+t_{r}^{L}\right)\left(1+t_{r}^{C}\right) \eta}{W H_{r} A^{C}\left(1+t_{r}^{C}\right)\left(1-t_{r}^{D}\right)\left(\left(\frac{1}{A^{C}} \frac{\eta}{\eta-1}\right)^{\frac{1}{1-g}}\left(\frac{1}{l}\right)\left(\frac{1}{g}\right)^{\frac{g}{1-g}}\right)}
$$

Furthermore, combining Equations 2.3, 2.4, 2.15, 5.5, and 5.8 results in:

$$
P_{r}^{L}=W
$$

for all $r$, which suggests that land prices are equalized across regions, and they are equal to the national wage rate. This implies that

$$
\sum_{r} \frac{Y_{r}^{C}}{A_{r}^{C}}=\frac{H Y_{r}^{L} f_{r}^{L}\left(1+t_{r}^{L}\right) \eta}{H_{r} A^{C}\left(1-t_{r}^{D}\right)\left(\left(\frac{1}{A^{C}} \frac{\eta}{\eta-1}\right)^{\frac{1}{1-g}}\left(\frac{1}{l}\right)\left(\frac{1}{g}\right)^{\frac{g}{1-g}}\right)}
$$


which suggests an expression for the ratio of population levels across regions $r$ and $i$ :

$$
\frac{H_{r}}{H_{i}}=\frac{Y_{r}^{L} f_{r}^{L}\left(1+t_{r}^{L}\right)\left(1-t_{i}^{D}\right)}{Y_{i}^{L} f_{i}^{L}\left(1+t_{i}^{L}\right)\left(1-t_{r}^{D}\right)}
$$

By using Equations 2.5, 5.3, and 5.4, we can write the ratio of consumption-goods for regions, say, $a$ and $b$ that:

$$
\frac{C_{a}^{C}}{C_{b}^{C}}=\frac{H_{a}\left(1+t_{b}^{C}\right)\left(1-t_{a}^{D}\right)}{H_{b}\left(1+t_{a}^{C}\right)\left(1-t_{b}^{D}\right)}
$$

By using Equations 2.14, 5.1, 5.4, $P_{r, i}=P_{i, i}\left(1+\tau_{r, i}\right)$, and $\theta_{r, i}=\left(1+\tau_{r, i}\right)^{(\eta-1)}$, we can write the goods traded from region $i$ to region $r$ as follows:

$$
C_{r, i}^{C}=\left(\frac{C_{r}^{C}}{1+\tau_{r, i}}\right)\left(\frac{A_{i}^{C}}{A^{C}}\right)^{\eta}
$$

which implies that the ratio of imports of region $i$ from regions $a$ and $b$ is:

$$
\frac{C_{i, a}^{C}}{C_{i, b}^{C}}=\left(\frac{1+\tau_{i, b}}{1+\tau_{i, a}}\right)\left(\frac{A_{a}^{C}}{A_{b}^{C}}\right)^{\eta}
$$

which is an expression for interregional trade suggesting that a destination region imports more goods from closer and high-tech (i.e., low-cost) regions.

Using Equation 5.12, it is implied that the ratio of exports of region $i$ to regions $a$ and $b$ is:

$$
\frac{C_{a, i}^{C}}{C_{b, i}^{C}}=\frac{\left(1+\tau_{b, i}\right) H_{a}\left(1+t_{b}^{C}\right)\left(\left(1-t_{a}^{D}\right)\right)}{\left(1+\tau_{a, i}\right) H_{b}\left(1+t_{a}^{C}\right)\left(\left(1-t_{b}^{D}\right)\right)}
$$

which suggests that a source region exports more goods to closer, higher populated, lower-sales-tax, or lower-dividend-income-tax regions.

Remember the market clearing condition (i.e., Equation 2.22):

$$
\begin{aligned}
Y_{r}^{C} & =\sum_{i}\left(\frac{\theta_{i, r}}{\left(1+\tau_{i, r}\right)^{\eta-1}}\left(\frac{P_{r, r}}{P_{i}}\right)^{-\eta}\left(C_{i}^{C}+G_{i}^{C}+G_{i}^{P}\right)\right) \\
& =\left(\frac{P_{r, r}}{P}\right)^{-\eta} \sum_{i}\left(C_{i}^{C}+G_{i}^{C}+G_{i}^{P}\right)
\end{aligned}
$$

where the second equality is due to $\theta_{i, r}=\left(1+\tau_{i, r}\right)^{(\eta-1)}$. This implies that the consumption-good production ratio of regions $a$ and $b$ is given by:

$$
\begin{aligned}
\frac{Y_{a}^{C}}{Y_{b}^{C}} & =\left(\frac{P_{a, a}}{P_{b, b}}\right)^{-\eta} \\
& =\left(\frac{A_{a}^{C}}{A_{b}^{C}}\right)^{\eta}
\end{aligned}
$$


where we have used Equation 5.3. This says that the relative private-sector production of a region is directly related to its production technology.

As indicated by Equation 2.24, the total cost of public good is restricted by the amount of taxes collected. Combining Equations 2.3, 2.4, and 2.24 the public-good production in region $r$ can be rewritten as

$$
Y_{r}^{P}=H_{r} A_{r}^{P} \Gamma(h)\left(\frac{\left(1-t_{r}^{D}\right)+t_{r}^{C}\left(\frac{1-t_{r}^{D}}{1+t_{r}^{C}}\right)+t_{r}^{W}\left(\frac{1-t_{r}^{D}}{1-t_{r}^{W}}\right)+t_{r}^{D}}{\left(\frac{1}{A^{C}} \frac{1}{g} \frac{\eta}{\eta-1}\right)^{\frac{g}{1-g}}\left(\frac{W}{l}\right)}\right)
$$

which implies that the public-good production ratio of regions $a$ and $b$ can be written as:

$$
\frac{Y_{a}^{P}}{Y_{b}^{P}}=\frac{H_{a} A_{a}^{P}\left(1-t_{a}^{D}\right)}{H_{b} A_{b}^{P}\left(1-t_{b}^{D}\right)}\left(\frac{1+\frac{t_{a}^{C}}{1+t_{a}^{C}}+\frac{t_{a}^{W}}{1-t_{a}^{W}}+\frac{t_{a}^{D}}{1-t_{a}^{D}}}{1+\frac{t_{b}^{C}}{1+t_{b}^{C}}+\frac{t_{b}^{W}}{1-t_{b}^{W}}+\frac{t_{b}^{D}}{1-t_{b}^{D}}}\right)
$$

From the cost-minimization problem of the consumption-good producing firms, it is known that:

$$
L_{r}^{C}=\frac{Y_{r}^{C}}{A_{r}^{C}}\left(\frac{P_{r}^{G}}{W} \frac{l}{g}\right)^{g}
$$

and

$$
L_{r}^{P}=\frac{Y_{r}^{P}}{A_{r}^{P}}\left(\frac{P_{r}^{P}}{W} \frac{l}{g}\right)^{g}
$$

which imply through Equation 5.3 that

$$
\frac{L_{r}^{C}}{L_{r}^{P}}=\frac{Y_{r}^{C}}{Y_{r}^{P}} \frac{A_{r}^{P}}{A_{r}^{C}}
$$

Using Equation 2.4, the total supply of workers in the country can be expressed as:

$$
\sum_{r} H_{r} N_{r}(h)=\sum_{r} \frac{H_{r} \Gamma(h)\left(1-t_{r}^{D}\right)}{W\left(1-t_{r}^{W}\right)}
$$

In equilibrium, total labor demand should be equal to total labor supply:

$$
\underbrace{\sum_{r} L_{r}^{C}}_{\text {Consumption Good }}+\underbrace{\sum_{r} L_{r}^{P}}_{\text {Public Good }}=\sum_{r} H_{r} N_{r}(h)
$$

which can be rewritten using Equations 2.4, 5.16 and 5.17 as

$$
\left(\frac{P_{r}^{G}}{W} \frac{l}{g}\right)^{g} \sum_{r}\left(\frac{Y_{r}^{C}}{A_{r}^{C}}+\frac{Y_{r}^{P}}{A_{r}^{P}}\right)=\sum_{r} \frac{H_{r} \Gamma(h)\left(1-t_{r}^{D}\right)}{W\left(1-t_{r}^{W}\right)}
$$


By combining Equations 5.5 and 5.15, we can write:

$$
Y_{r}^{P}=H_{r} \frac{A_{r}^{P}}{H}\left(\frac{1}{\eta-1}\right)\left(\sum_{r} \frac{Y_{r}^{C}}{A_{r}^{C}}\right)\left(t_{r}^{L}\left(\frac{\left(1-t_{r}^{D}\right)}{\left(1+t_{r}^{L}\right)}\right)+t_{r}^{C}\left(\frac{\left(1-t_{r}^{D}\right)}{\left(1+t_{r}^{C}\right)}\right)+t_{r}^{W} \frac{\left(1-t_{r}^{D}\right)}{\left(1-t_{r}^{W}\right)}+t_{r}^{D}\right)
$$

which means that

$$
\left(\sum_{r} \frac{Y_{r}^{C}}{A_{r}^{C}}\right)=\frac{H Y_{r}^{P}(\eta-1)}{H_{r} A_{r}^{P}\left(1-t_{r}^{D}\right)\left(1+\frac{t_{r}^{C}}{1+t_{r}^{C}}+\frac{t_{r}^{W}}{1-t_{r}^{W}}+\frac{t_{r}^{D}}{1-t_{r}^{D}}\right)}
$$

Combining this with Equations 5.5 and 5.20, after some basic algebra, gives:

$$
\sum_{r} \frac{Y_{r}^{P}}{A_{r}^{P}}=\frac{Y_{r}^{P}}{A_{r}^{P}}\left(\frac{H\left(\left(\frac{1}{H} \frac{1}{\eta-1}\left(\frac{W}{l}\right)^{\frac{l}{1-g}}\right)\left(\sum_{r} \frac{H_{r}\left(1-t_{r}^{D}\right)}{W\left(1-t_{r}^{W}\right)}\right)-1\right)}{H_{r}\left(1-t_{r}^{D}\right)\left(\frac{1}{\eta-1}\right)\left(1+\frac{t_{r}^{C}}{1+t_{r}^{C}}+\frac{t_{r}^{W}}{1-t_{r}^{W}}+\frac{t_{r}^{D}}{1-t_{r}^{D}}\right)}\right)
$$

which implies that

$$
l=\frac{\frac{1}{\eta-1}\left(\sum_{r} \frac{H_{r}\left(1-t_{r}^{D}\right)}{\left(1-t_{r}^{W}\right)}\right)}{H+\frac{1}{\eta-1} \sum_{r} H_{r}\left(1-t_{r}^{D}\right)\left(1+\frac{t_{r}^{C}}{1+t_{r}^{C}}+\frac{t_{r}^{W}}{1-t_{r}^{W}}+\frac{t_{r}^{D}}{1-t_{r}^{D}}\right)}
$$

In a special case in which taxes are zero (and, thus, there is no public-good production or consumption), we have:

$$
l=\frac{1}{\eta}
$$

which suggests that labor share in production is equal to the net markup in the absence of taxes and/or a public sector. This implies that

$$
\begin{aligned}
g & =1-l \\
& =\frac{\eta-1}{\eta}
\end{aligned}
$$

which suggests that the intermediate-input share in production is also related to the elasticity of substitution across goods in the absence of taxes and/or a public sector.

Combining Equation 5.10 with Equation 5.22 results in the following expression for the public good produced in region $r$ :

$$
Y_{r}^{P}=\frac{Y_{r}^{L} f_{r}^{L} A_{r}^{P}\left(1+t_{r}^{L}\right)\left(1+\frac{t_{r}^{C}}{1+t_{r}^{C}}+\frac{t_{r}^{W}}{1-t_{r}^{W}}+\frac{t_{r}^{D}}{1-t_{r}^{D}}\right)}{\left(\frac{1}{A^{C}} \frac{\eta}{\eta-1} \frac{1}{g}\right)^{\frac{g}{1-g}} \frac{1}{l}}
$$


The cost-minimization problem of the consumption-good producing firm results in the following demand for intermediate inputs:

$$
\begin{aligned}
G_{r}^{C} & =\frac{g W L_{r}^{C}}{l P} \\
& =\frac{Y_{r}^{C}}{A_{r}^{C}}\left(\frac{P}{W} \frac{l}{g}\right)^{g-1}
\end{aligned}
$$

By using Equations 5.4 and 5.23, the last expression can be rewritten as:

$$
G_{r}^{C}=\left(\frac{\eta-1}{\eta}\right) \frac{Y_{r}^{C} A^{C} g}{A_{r}^{C}}
$$

Similarly, for the intermediate input of the public sector, we can write

$$
G_{r}^{P}=\left(\frac{\eta-1}{\eta}\right) \frac{Y_{r}^{P} A^{C} g}{A_{r}^{P}}
$$

Hence

$$
\frac{G_{r}^{C}}{G_{r}^{P}}=\frac{Y_{r}^{C} A_{r}^{P}}{Y_{r}^{P} A_{r}^{C}}
$$

Now, in Equation 5.13, we have information for $C_{i}^{C}$ for all $i$ (through Equation 5.7), for $G_{i}^{C}$ for all $i$ (through Equation 5.24), and for $G_{i}^{P}$ for all $i$ (through Equation 5.25). Hence Equation 5.13 can be rewritten as:

$$
Y_{r}^{C}=\frac{\left(A^{C}\right)^{1-\eta}}{\eta\left(A_{r}^{C}\right)^{-\eta}} \sum_{i}\left(\left(\frac{H_{i}\left(1-t_{i}^{D}\right)}{H\left(1+t_{i}^{C}\right)}\right)\left(\sum_{r} \frac{Y_{r}^{C}}{A_{r}^{C}}\right)+(\eta-1)\left(\frac{Y_{i}^{C} g}{A_{i}^{C}}+\frac{Y_{i}^{P} g}{A_{i}^{P}}\right)\right)
$$

Combining this with Equation 5.21 results in:

$$
Y_{r}^{C}=\frac{\left(A^{C}\right)^{1-\eta}}{\eta\left(A_{r}^{C}\right)^{-\eta}}\left(\sum_{r} \frac{Y_{r}^{C}}{A_{r}^{C}}\right)\left(\begin{array}{c}
(\eta-1) g+\sum_{i}\left(\frac{H_{i}\left(1-t_{i}^{D}\right)}{H\left(1+t_{i}^{C}\right)}\right) \\
+\sum_{i} \frac{g H_{i}\left(1-t_{i}^{D}\right)}{H}\left(1+\frac{t_{i}^{C}}{1+t_{i}^{C}}+\frac{t_{i}^{W}}{1-t_{i}^{W}}+\frac{t_{i}^{D}}{1-t_{i}^{D}}\right)
\end{array}\right)
$$

Combining Equations 5.10 and 5.26 results in an expression for the production of consumption good in region $r$ :

$$
Y_{r}^{C}=\frac{Y_{r}^{L} f_{r}^{L}\left(1+t_{r}^{L}\right)\left(\begin{array}{c}
g H(\eta-1)+\sum_{i}\left(\frac{H_{i}\left(1-t_{i}^{D}\right)}{\left(1+t_{i}^{C}\right)}\right) \\
+\sum_{i} g H_{i}\left(1-t_{i}^{D}\right)\left(1+\frac{t_{i}^{C}}{1+t_{i}^{C}}+\frac{t_{i}^{W}}{1-t_{i}^{W}}+\frac{t_{i}^{D}}{1-t_{i}^{D}}\right)
\end{array}\right)}{H_{r}\left(1-t_{r}^{D}\right)\left(\frac{A^{C}}{A_{r}^{C}}\right)^{\eta}\left(\left(\frac{1}{A^{C}} \frac{\eta}{\eta-1}\right)^{\frac{1}{1-g}}\left(\frac{1}{l}\right)\left(\frac{1}{g}\right)^{\frac{g}{1-g}}\right)}
$$

which implies that the ratio of production of consumption good across regions $r$ and $i$ is:

$$
\frac{Y_{r}^{C}}{Y_{i}^{C}}=\left(\frac{A_{r}^{C}}{A_{i}^{C}}\right)^{\eta} \frac{Y_{r}^{L} f_{r}^{L}\left(1+t_{r}^{L}\right)}{Y_{i}^{L} f_{i}^{L}\left(1+t_{i}^{L}\right)} \frac{H_{i}\left(1-t_{i}^{D}\right)}{H_{r}\left(1-t_{r}^{D}\right)}
$$


Recall individual utility in Equation 2.1 which is supposed to be the same across regions according to Equation 2.20. Using Equation 2.3, 2.4, 2.15, 5.7, 5.21, 5.5, Equation 2.1 can be rewritten as:

$$
\begin{aligned}
U_{r}(h) \equiv & \left.\log \left(\frac{\left(1-t_{r}^{D}\right) A^{C}}{H\left(1+t_{r}^{C}\right) \eta}\right) \sum_{r} \frac{Y_{r}^{C}}{A_{r}^{C}}\right) \\
& +\log \left(\frac{\left(1-t_{r}^{D}\right) \frac{1}{H} \frac{1}{\eta-1}\left(\frac{1}{A^{C}} \frac{1}{g} \frac{\eta}{\eta-1}\right)^{\frac{g}{1-g}}\left(\frac{W}{l}\right) \sum_{r} \frac{Y_{r}^{C}}{A_{r}^{C}}}{P_{r}^{L}\left(1+t_{r}^{L}\right)}\right) \\
& +\log \left(\frac{A_{r}^{P}}{H}\left(\frac{1-t_{r}^{D}}{\eta-1}\right)\left(\sum_{r} \frac{Y_{r}^{C}}{A_{r}^{C}}\right)\left(1+\frac{t_{r}^{C}}{1+t_{r}^{C}}+\frac{t_{r}^{W}}{1-t_{r}^{W}}+\frac{t_{r}^{D}}{1-t_{r}^{D}}\right)\right) \\
& -\log \left(\frac{\left(1-t_{r}^{D}\right) \frac{1}{H} \frac{1}{\eta-1}\left(\frac{1}{A^{C}} \frac{1}{g} \frac{\eta}{\eta-1}\right)^{\frac{g}{1-g}}\left(\frac{1}{l}\right) \sum_{r} \frac{Y_{r}^{C}}{A_{r}^{C}}}{\left(1-t_{r}^{W}\right)}\right)
\end{aligned}
$$

When individual utilities are the same across regions, we have the following individual-utility ratio across regions $r$ and $i$ :

$$
\begin{aligned}
\frac{\exp \left(U_{r}(h)\right)}{\exp \left(U_{i}(h)\right)} \equiv & \left(\frac{\left(1+t_{i}^{C}\right)\left(1-t_{r}^{D}\right)}{\left(1+t_{r}^{C}\right)\left(1-t_{i}^{D}\right)}\right)\left(\frac{P_{i}^{L}\left(1+t_{i}^{L}\right)\left(1-t_{r}^{W}\right)}{P_{r}^{L}\left(1+t_{r}^{L}\right)\left(1-t_{i}^{W}\right)}\right) \\
& \times\left(\frac{\left(A_{r}^{P}\left(1-t_{r}^{D}\right)\left(1+\frac{t_{r}^{C}}{1+t_{r}^{C}}+\frac{t_{r}^{W}}{1-t_{r}^{W}}+\frac{t_{r}^{D}}{1-t_{r}^{D}}\right)\right)}{\left(A_{i}^{P}\left(1-t_{i}^{D}\right)\left(1+\frac{t_{i}^{C}}{1+t_{i}^{C}}+\frac{t_{i}^{W}}{1-t_{i}^{W}}+\frac{t_{i}^{D}}{1-t_{i}^{D}}\right)\right)}\right) \\
= & 1
\end{aligned}
$$

Combining this with Equation 5.9 results in the equilibrium ratio of public-good production technologies across regions $r$ and $i$ :

$$
\frac{A_{r}^{P}}{A_{i}^{P}}=\frac{\left(1+t_{r}^{L}\right)\left(1-t_{i}^{W}\right)\left(1+t_{r}^{C}\right)\left(1-t_{i}^{D}\right)\left(1+\frac{t_{i}^{C}\left(1-t_{i}^{D}\right)}{1+t_{i}^{C}}+\frac{t_{i}^{W}\left(1-t_{i}^{D}\right)}{1-t_{i}^{W}}\right)}{\left(1+t_{i}^{L}\right)\left(1-t_{r}^{W}\right)\left(1+t_{i}^{C}\right)\left(1-t_{r}^{D}\right)\left(1+\frac{t_{r}^{C}\left(1-t_{r}^{D}\right)}{1+t_{r}^{C}}+\frac{t_{r}^{W}\left(1-t_{r}^{D}\right)}{1-t_{r}^{W}}\right)}
$$

where the right hand side consists of region-specific taxes only.

\section{Appendix B: Closed-Form Solution Summary}

This section provides a summary of the closed-form solution of all region-specific endogenous variables in terms of region-specific exogenous variables and parameters which are tax rates, technology 
levels (of both private and public sectors), iceberg trade costs, land sizes, elasticity of substitution across goods, the fraction of land that is supplied, and total population in all regions. After setting $W=1$ as the numeraire, we have the following closed-form expressions:

$$
\begin{aligned}
& H_{r}=\frac{Y_{r}^{L} f_{r}^{L}\left(1+t_{r}^{L}\right) H}{\left(1-t_{r}^{D}\right)\left(\sum_{i} \frac{Y_{i}^{L} f_{i}^{L}\left(1+t_{i}^{L}\right)}{\left(1-t_{i}^{D}\right)}\right)} \\
& l=\frac{\frac{1}{\eta-1}\left(\sum_{r} \frac{H_{r}\left(1-t_{r}^{D}\right)}{\left(1-t_{r}^{W}\right)}\right)}{H+\frac{1}{\eta-1} \sum_{r} H_{r}\left(1-t_{r}^{D}\right)\left(1+\frac{t_{r}^{C}}{1+t_{r}^{C}}+\frac{t_{r}^{W}}{1-t_{r}^{W}}+\frac{t_{r}^{D}}{1-t_{r}^{D}}\right)} \\
& g=1-l \\
& A^{C}=\left(\sum_{i}\left(A_{i}^{C}\right)^{\eta-1}\right)^{\frac{1}{\eta-1}} \\
& P_{r}^{L}=P_{i}^{L}=P^{L}=1 \quad \text { for all } r, i \\
& P_{r, r}=\frac{\left(A^{C}\right)^{\frac{-g}{1-g}}}{A_{r}^{C}}\left(\frac{\eta}{\eta-1}\right)^{\frac{1}{1-g}}\left(\frac{1}{l}\right)\left(\frac{1}{g}\right)^{\frac{g}{1-g}} \\
& P_{i, r}=\left(D_{i, r}\right)^{\delta} \frac{\left(A^{C}\right)^{\frac{-g}{1-g}}}{A_{r}^{C}}\left(\frac{\eta}{\eta-1}\right)^{\frac{1}{1-g}}\left(\frac{1}{l}\right)\left(\frac{1}{g}\right)^{\frac{g}{1-g}} \\
& P_{i, r}=P_{i, r}^{C}=P_{i, r}^{G}=P_{i, r}^{P} \\
& P_{r}^{C}=P_{r}^{G}=P_{r}^{P}=P_{r}=P_{i}=P \quad \text { for all } r \text { and } i \\
& P=\left(\frac{1}{A^{C}}\left(\frac{\eta}{\eta-1}\left(\frac{1}{l}\right)^{l}\left(\frac{1}{g}\right)^{g}\right)\right)^{\frac{1}{1-g}} \\
& C_{r}^{C}(h)=\frac{Y_{r}^{L} f_{r}^{L}\left(1+t_{r}^{L}\right)}{H_{r}\left(1+t_{r}^{C}\right)\left(\left(\frac{1}{A^{C}} \frac{\eta}{\eta-1}\right)^{\frac{1}{1-g}}\left(\frac{1}{l}\right)\left(\frac{1}{g}\right)^{\frac{g}{1-g}}\right)} \\
& C_{r}^{C}=\frac{Y_{r}^{L} f_{r}^{L}\left(1+t_{r}^{L}\right)}{\left(1+t_{r}^{C}\right)\left(\left(\frac{1}{A^{C}} \frac{\eta}{\eta-1}\right)^{\frac{1}{1-g}}\left(\frac{1}{l}\right)\left(\frac{1}{g}\right)^{\frac{g}{1-g}}\right)}
\end{aligned}
$$




$$
\begin{aligned}
& M C_{r}^{C}=\left(\frac{1}{A_{r}^{C} l}\right)\left(\frac{1}{A^{C}} \frac{1}{g} \frac{\eta}{\eta-1}\right)^{\frac{g}{1-g}} \\
& M C_{r}^{P}=\left(\frac{1}{A_{r}^{P} l}\right)\left(\frac{1}{A^{C}} \frac{1}{g} \frac{\eta}{\eta-1}\right)^{\frac{g}{1-g}} \\
& \Gamma=\left(\sum_{i} \frac{Y_{i}^{L} f_{i}^{L}\left(1+t_{i}^{L}\right)}{\left(1-t_{i}^{D}\right)}\right) \\
& \Gamma(h)=\frac{1}{H}\left(\sum_{i} \frac{Y_{i}^{L} f_{i}^{L}\left(1+t_{i}^{L}\right)}{\left(1-t_{i}^{D}\right)}\right) \\
& N_{r}(h)=\frac{\left(1-t_{r}^{D}\right)}{H\left(1-t_{r}^{W}\right)}\left(\sum_{i} \frac{Y_{i}^{L} f_{i}^{L}\left(1+t_{i}^{L}\right)}{\left(1-t_{i}^{D}\right)}\right) \\
& N_{r}=\frac{Y_{r}^{L} f_{r}^{L}\left(1+t_{r}^{L}\right)}{\left(1-t_{r}^{W}\right)} \\
& C_{r, i}^{C}=\frac{Y_{r}^{L} f_{r}^{L}\left(1+t_{r}^{L}\right)\left(\frac{A_{i}^{C}}{A^{C}}\right)^{\eta}}{\left(1+\tau_{r, i}\right)\left(1+t_{r}^{C}\right)\left(\left(\frac{1}{A^{C}} \frac{\eta}{\eta-1}\right)^{\frac{1}{1-g}}\left(\frac{1}{l}\right)\left(\frac{1}{g}\right)^{\frac{g}{1-g}}\right)} \\
& Y_{r}^{C}=\frac{Y_{r}^{L} f_{r}^{L}\left(1+t_{r}^{L}\right)\left(\begin{array}{c}
g H(\eta-1)+\sum_{i}\left(\frac{H_{i}\left(1-t_{i}^{D}\right)}{\left(1+t_{i}^{C}\right)}\right) \\
+\sum_{i} g H_{i}\left(1-t_{i}^{D}\right)\left(1+\frac{t_{i}^{C}}{1+t_{i}^{C}}+\frac{t_{i}^{W}}{1-t_{i}^{W}}+\frac{t_{i}^{D}}{1-t_{i}^{D}}\right)
\end{array}\right)}{H_{r}\left(1-t_{r}^{D}\right)\left(\frac{A^{C}}{A_{r}^{C}}\right)^{\eta}\left(\left(\frac{1}{A^{C}} \frac{\eta}{\eta^{\frac{1}{1}}}\right)^{\frac{1}{1-g}}\left(\frac{1}{l}\right)\left(\frac{1}{g}\right)^{\frac{g}{1-g}}\right)} \\
& Y_{r}^{P}=H_{r} A_{r}^{P}\left(\frac{1+t_{r}^{C}\left(\frac{1-t_{r}^{D}}{1+t_{r}^{C}}\right)+t_{r}^{W}\left(\frac{1-t_{r}^{D}}{1-t_{r}^{W}}\right)}{H\left(\frac{1}{A^{C}} \frac{1}{g} \frac{\eta}{\eta-1}\right)^{\frac{g}{1-g}} \frac{1}{l}}\right)\left(\sum_{i} \frac{Y_{i}^{L} f_{i}^{L}\left(1+t_{i}^{L}\right)}{\left(1-t_{i}^{D}\right)}\right) \\
& G_{r}^{C}=\frac{\left(\frac{\eta-1}{\eta}\right) g Y_{r}^{L} f_{r}^{L}\left(1+t_{r}^{L}\right)\left(\begin{array}{c}
g H(\eta-1)+\sum_{i}\left(\frac{H_{i}\left(1-t_{i}^{D}\right)}{\left(1+t_{i}^{C}\right)}\right) \\
+\sum_{i} g H_{i}\left(1-t_{i}^{D}\right)\left(1+\frac{t_{i}^{C}}{1+t_{i}^{C}}+\frac{t_{i}^{W}}{1-t_{i}^{W}}+\frac{t_{i}^{D}}{1-t_{i}^{D}}\right)
\end{array}\right)}{H_{r}\left(1-t_{r}^{D}\right)\left(\frac{A^{C}}{A_{r}^{C}}\right)^{\eta-1}\left(\left(\frac{1}{A^{C}} \frac{\eta}{\eta-1}\right)^{\frac{1}{1-g}}\left(\frac{1}{l}\right)\left(\frac{1}{g}\right)^{\frac{g}{1-g}}\right)}
\end{aligned}
$$




$$
\begin{aligned}
& G_{r, i}^{C}=\frac{\left(\frac{\eta-1}{\eta}\right) g Y_{r}^{L} f_{r}^{L}\left(1+t_{r}^{L}\right)\left(\begin{array}{c}
g H(\eta-1)+\sum_{i}\left(\frac{H_{i}\left(1-t_{i}^{D}\right)}{\left(1+t_{i}^{C}\right)}\right) \\
+\sum_{i} g H_{i}\left(1-t_{i}^{D}\right)\left(1+\frac{t_{i}^{C}}{1+t_{i}^{C}}+\frac{t_{i}^{W}}{1-t_{i}^{W}}+\frac{t_{i}^{D}}{1-t_{i}^{D}}\right)
\end{array}\right)}{\left(1+\tau_{r, i}\right) H_{r}\left(1-t_{r}^{D}\right)\left(\frac{A^{C}}{A_{r}^{C}}\right)^{2 \eta-1}\left(\left(\frac{1}{A^{C}} \frac{\eta}{\eta-1}\right)^{\frac{1}{1-g}}\left(\frac{1}{l}\right)\left(\frac{1}{g}\right)^{\frac{g}{1-g}}\right)} \\
& G_{r}^{P}=\left(\frac{\eta-1}{\eta}\right) A^{C} g H_{r}\left(\frac{1+t_{r}^{C}\left(\frac{1-t_{r}^{D}}{1+t_{r}^{C}}\right)+t_{r}^{W}\left(\frac{1-t_{r}^{D}}{1-t_{r}^{W}}\right)}{H\left(\frac{1}{A^{C}} \frac{1}{g} \frac{\eta}{\eta-1}\right)^{\frac{g}{1-g}}\left(\frac{1}{l}\right)}\right)\left(\sum_{i} \frac{Y_{i}^{L} f_{i}^{L}\left(1+t_{i}^{L}\right)}{\left(1-t_{i}^{D}\right)}\right) \\
& =\left(\frac{\eta-1}{\eta}\right) \frac{Y_{r}^{L} f_{r}^{L}\left(1+t_{r}^{L}\right)}{\left(1-t_{r}^{D}\right)}\left(\frac{1+t_{r}^{C}\left(\frac{1-t_{r}^{D}}{1+t_{r}^{C}}\right)+t_{r}^{W}\left(\frac{1-t_{r}^{D}}{1-t_{r}^{W}}\right)}{\left(\left(\frac{1}{A^{C}} \frac{\eta}{\eta-1}\right)^{\frac{1}{1-g}}\left(\frac{1}{l}\right)\left(\frac{1}{g}\right)^{\frac{g}{1-g}}\right)}\right) \\
& G_{r, i}^{P}=\frac{H_{r} A^{C} g}{\left(1+\tau_{r, i}\right)}\left(\frac{A^{C}}{A_{r}^{C}}\right)^{-\eta}\left(\frac{\eta-1}{\eta}\right) \\
& \times\left(\frac{1+t_{r}^{C}\left(\frac{1-t_{r}^{D}}{1+t_{r}^{C}}\right)+t_{r}^{W}\left(\frac{1-t_{r}^{D}}{1-t_{r}^{W}}\right)}{H\left(\frac{1}{A^{C}} \frac{1}{g} \frac{\eta}{\eta-1}\right)^{\frac{g}{1-g}}\left(\frac{1}{l}\right)}\right)\left(\sum_{i} \frac{Y_{i}^{L} f_{i}^{L}\left(1+t_{i}^{L}\right)}{\left(1-t_{i}^{D}\right)}\right)
\end{aligned}
$$

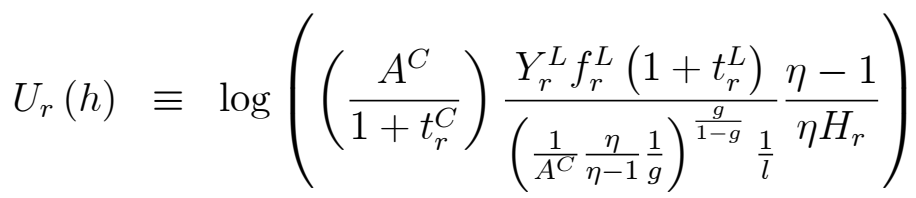

$$
\begin{aligned}
& +\log \left(\frac{Y_{r}^{L} f_{r}^{L}}{H_{r}}\right) \\
& +\log \left(\frac{A_{r}^{P}}{H_{r}}\left(\frac{Y_{r}^{L} f_{r}^{L}\left(1+t_{r}^{L}\right)}{\left(\frac{1}{A^{C}} \frac{\eta}{\eta-1} \frac{1}{g}\right)^{\frac{g}{1-g}} \frac{1}{l}}\right)\left(1+\frac{t_{r}^{C}}{1+t_{r}^{C}}+\frac{t_{r}^{W}}{1-t_{r}^{W}}+\frac{t_{r}^{D}}{1-t_{r}^{D}}\right)\right) \\
& -\log \left(\frac{Y_{r}^{L} f_{r}^{L}\left(1+t_{r}^{L}\right)}{\left(1-t_{r}^{W}\right) H_{r}}\right)
\end{aligned}
$$


Table 1 - Elasticities of Endogenous Variables with respect to Wage-Income Tax Rates

\begin{tabular}{|c|c|c|c|c|c|c|c|c|c|c|c|c|}
\hline \multirow[b]{2}{*}{ STATE } & \multicolumn{6}{|c|}{ NATIONWIDE WAGE-INCOME TAX RATES } & \multicolumn{6}{|c|}{ STATE-LEVEL WAGE-INCOME TAX RATES } \\
\hline & CON & LAN & PUB & HOW & POP & WEL & CON & LAN & PUB & HOW & POP & WEL \\
\hline Alabama & -1.59 & 0.00 & -0.49 & 1.69 & 0.00 & -3.77 & -0.02 & 0.00 & 1.66 & 1.69 & 0.00 & -0.05 \\
\hline Alaska & -1.59 & 0.00 & -0.49 & 1.69 & 0.00 & -3.77 & 0.00 & 0.00 & 1.68 & 1.69 & 0.00 & -0.02 \\
\hline Arizona & -1.59 & 0.00 & -0.38 & 1.80 & 0.00 & -3.77 & -0.03 & 0.00 & 1.75 & 1.80 & 0.00 & -0.08 \\
\hline Arkansas & -1.59 & 0.00 & -0.26 & 1.92 & 0.00 & -3.77 & -0.02 & 0.00 & 1.89 & 1.92 & 0.00 & -0.04 \\
\hline California & -1.59 & 0.00 & -0.23 & 1.95 & 0.00 & -3.77 & -0.21 & 0.00 & 1.73 & 1.95 & 0.00 & -0.43 \\
\hline Colorado & -1.59 & 0.00 & -0.35 & 1.83 & 0.00 & -3.77 & -0.03 & 0.00 & 1.80 & 1.83 & 0.00 & -0.06 \\
\hline Connecticut & -1.59 & 0.00 & -0.33 & 1.85 & 0.00 & -3.77 & -0.02 & 0.00 & 1.81 & 1.85 & 0.00 & -0.05 \\
\hline Delaware & -1.59 & 0.00 & -0.31 & 1.86 & 0.00 & -3.77 & 0.00 & 0.00 & 1.85 & 1.86 & 0.00 & -0.02 \\
\hline Washington DC & -1.59 & 0.00 & -0.26 & 1.92 & 0.00 & -3.77 & 0.00 & 0.00 & 1.90 & 1.92 & 0.00 & -0.02 \\
\hline Florida & -1.59 & 0.00 & -0.49 & 1.69 & 0.00 & -3.77 & -0.09 & 0.00 & 1.59 & 1.69 & 0.00 & -0.19 \\
\hline Georgia & -1.59 & 0.00 & -0.30 & 1.88 & 0.00 & -3.77 & -0.05 & 0.00 & 1.82 & 1.88 & 0.00 & -0.12 \\
\hline Hawaii & -1.59 & 0.00 & -0.23 & 1.95 & 0.00 & -3.77 & -0.01 & 0.00 & 1.93 & 1.95 & 0.00 & -0.02 \\
\hline Idaho & -1.59 & 0.00 & -0.23 & 1.95 & 0.00 & -3.77 & -0.01 & 0.00 & 1.92 & 1.95 & 0.00 & -0.03 \\
\hline Illinois & -1.59 & 0.00 & -0.40 & 1.78 & 0.00 & -3.77 & -0.07 & 0.00 & 1.70 & 1.78 & 0.00 & -0.15 \\
\hline Indiana & -1.59 & 0.00 & -0.39 & 1.79 & 0.00 & -3.77 & -0.03 & 0.00 & 1.75 & 1.79 & 0.00 & -0.08 \\
\hline lowa & -1.59 & 0.00 & -0.49 & 1.69 & 0.00 & -3.77 & -0.01 & 0.00 & 1.66 & 1.69 & 0.00 & -0.04 \\
\hline Kansas & -1.59 & 0.00 & -0.28 & 1.90 & 0.00 & -3.77 & -0.02 & 0.00 & 1.86 & 1.90 & 0.00 & -0.05 \\
\hline Kentucky & -1.59 & 0.00 & -0.31 & 1.87 & 0.00 & -3.77 & -0.02 & 0.00 & 1.84 & 1.87 & 0.00 & -0.06 \\
\hline Louisiana & -1.59 & 0.00 & -0.49 & 1.69 & 0.00 & -3.77 & -0.02 & 0.00 & 1.66 & 1.69 & 0.00 & -0.05 \\
\hline Maine & -1.59 & 0.00 & -0.21 & 1.97 & 0.00 & -3.77 & -0.01 & 0.00 & 1.95 & 1.97 & 0.00 & -0.03 \\
\hline Maryland & -1.59 & 0.00 & -0.34 & 1.84 & 0.00 & -3.77 & -0.03 & 0.00 & 1.80 & 1.84 & 0.00 & -0.07 \\
\hline Massachusetts & -1.59 & 0.00 & -0.32 & 1.86 & 0.00 & -3.77 & -0.03 & 0.00 & 1.81 & 1.86 & 0.00 & -0.08 \\
\hline Michigan & -1.59 & 0.00 & -0.37 & 1.81 & 0.00 & -3.77 & -0.05 & 0.00 & 1.74 & 1.81 & 0.00 & -0.12 \\
\hline Minnesota & -1.59 & 0.00 & -0.26 & 1.92 & 0.00 & -3.77 & -0.03 & 0.00 & 1.87 & 1.92 & 0.00 & -0.07 \\
\hline Mississippi & -1.59 & 0.00 & -0.33 & 1.85 & 0.00 & -3.77 & -0.02 & 0.00 & 1.82 & 1.85 & 0.00 & -0.04 \\
\hline Missouri & -1.59 & 0.00 & -0.49 & 1.69 & 0.00 & -3.77 & -0.03 & 0.00 & 1.65 & 1.69 & 0.00 & -0.07 \\
\hline Montana & -1.59 & 0.00 & -0.49 & 1.69 & 0.00 & -3.77 & 0.00 & 0.00 & 1.68 & 1.69 & 0.00 & -0.02 \\
\hline Nebraska & -1.59 & 0.00 & -0.27 & 1.91 & 0.00 & -3.77 & -0.01 & 0.00 & 1.88 & 1.91 & 0.00 & -0.04 \\
\hline Nevada & -1.59 & 0.00 & -0.49 & 1.69 & 0.00 & -3.77 & -0.01 & 0.00 & 1.67 & 1.69 & 0.00 & -0.03 \\
\hline New Hampshire & -1.59 & 0.00 & -0.49 & 1.69 & 0.00 & -3.77 & -0.01 & 0.00 & 1.67 & 1.69 & 0.00 & -0.03 \\
\hline New Jersey & -1.59 & 0.00 & -0.38 & 1.80 & 0.00 & -3.77 & -0.05 & 0.00 & 1.73 & 1.80 & 0.00 & -0.11 \\
\hline New Mexico & -1.59 & 0.00 & -0.32 & 1.86 & 0.00 & -3.77 & -0.01 & 0.00 & 1.84 & 1.86 & 0.00 & -0.03 \\
\hline New York & -1.59 & 0.00 & -0.27 & 1.91 & 0.00 & -3.77 & -0.11 & 0.00 & 1.79 & 1.91 & 0.00 & -0.24 \\
\hline North Carolina & -1.59 & 0.00 & -0.26 & 1.92 & 0.00 & -3.77 & -0.05 & 0.00 & 1.85 & 1.92 & 0.00 & -0.12 \\
\hline North Dakota & -1.59 & 0.00 & -0.37 & 1.81 & 0.00 & -3.77 & 0.00 & 0.00 & 1.79 & 1.81 & 0.00 & -0.02 \\
\hline Ohio & -1.59 & 0.00 & -0.36 & 1.81 & 0.00 & -3.77 & -0.06 & 0.00 & 1.74 & 1.81 & 0.00 & -0.14 \\
\hline Oklahoma & -1.59 & 0.00 & -0.29 & 1.89 & 0.00 & -3.77 & -0.02 & 0.00 & 1.86 & 1.89 & 0.00 & -0.05 \\
\hline Oregon & -1.59 & 0.00 & -0.19 & 1.99 & 0.00 & -3.77 & -0.02 & 0.00 & 1.96 & 1.99 & 0.00 & -0.06 \\
\hline Pennsylvania & -1.59 & 0.00 & -0.40 & 1.78 & 0.00 & -3.77 & -0.07 & 0.00 & 1.70 & 1.78 & 0.00 & -0.15 \\
\hline Rhode Island & -1.59 & 0.00 & -0.26 & 1.92 & 0.00 & -3.77 & -0.01 & 0.00 & 1.89 & 1.92 & 0.00 & -0.03 \\
\hline South Carolina & -1.59 & 0.00 & -0.26 & 1.92 & 0.00 & -3.77 & -0.03 & 0.00 & 1.88 & 1.92 & 0.00 & -0.06 \\
\hline South Dakota & -1.59 & 0.00 & -0.49 & 1.69 & 0.00 & -3.77 & 0.00 & 0.00 & 1.67 & 1.69 & 0.00 & -0.02 \\
\hline Tennessee & -1.59 & 0.00 & -0.49 & 1.69 & 0.00 & -3.77 & -0.03 & 0.00 & 1.65 & 1.69 & 0.00 & -0.07 \\
\hline Texas & -1.59 & 0.00 & -0.49 & 1.69 & 0.00 & -3.77 & -0.12 & 0.00 & 1.56 & 1.69 & 0.00 & -0.25 \\
\hline Utah & -1.59 & 0.00 & -0.26 & 1.92 & 0.00 & -3.77 & -0.02 & 0.00 & 1.89 & 1.92 & 0.00 & -0.04 \\
\hline Vermont & -1.59 & 0.00 & -0.26 & 1.92 & 0.00 & -3.77 & 0.00 & 0.00 & 1.90 & 1.92 & 0.00 & -0.03 \\
\hline Virginia & -1.59 & 0.00 & -0.31 & 1.87 & 0.00 & -3.77 & -0.04 & 0.00 & 1.82 & 1.87 & 0.00 & -0.10 \\
\hline Washington & -1.59 & 0.00 & -0.49 & 1.69 & 0.00 & -3.77 & -0.03 & 0.00 & 1.65 & 1.69 & 0.00 & -0.07 \\
\hline West Virginia & -1.59 & 0.00 & -0.35 & 1.83 & 0.00 & -3.77 & -0.01 & 0.00 & 1.81 & 1.83 & 0.00 & -0.03 \\
\hline Wisconsin & -1.59 & 0.00 & -0.28 & 1.90 & 0.00 & -3.77 & -0.03 & 0.00 & 1.85 & 1.90 & 0.00 & -0.08 \\
\hline Wyoming & -1.59 & 0.00 & -0.49 & 1.69 & 0.00 & -3.77 & 0.00 & 0.00 & 1.68 & 1.69 & 0.00 & -0.01 \\
\hline
\end{tabular}

Notes: CON stands for per capita consumption good, LAN for per capita land, PUB for per capita public good, HOW for per capita hours of work, POP for population, WEL for welfare measured by individual utility. 
Table 2 - Elasticities of Endogenous Variables with respect to Dividend-Income Tax Rates

\begin{tabular}{|c|c|c|c|c|c|c|c|c|c|c|c|c|}
\hline \multirow[b]{2}{*}{ STATE } & \multicolumn{6}{|c|}{ NATIONWIDE DIVIDEND-INCOME TAX RATES } & \multicolumn{6}{|c|}{ STATE-LEVEL DIVIDEND-INCOME TAX RATES } \\
\hline & CON & LAN & PUB & HOW & POP & WEL & CON & LAN & PUB & HOW & POP & WEL \\
\hline Alabama & 2.15 & 0.14 & 3.10 & 0.14 & -0.14 & 5.25 & -1.63 & -1.66 & 1.72 & -1.66 & 1.66 & 0.09 \\
\hline Alaska & 2.15 & 0.14 & 3.10 & 0.14 & -0.14 & 5.25 & -1.68 & -1.69 & 1.66 & -1.69 & 1.69 & -0.02 \\
\hline Arizona & 2.04 & 0.04 & 3.21 & 0.04 & -0.04 & 5.25 & -1.72 & -1.76 & 1.84 & -1.76 & 1.76 & 0.12 \\
\hline Arkansas & 1.92 & -0.08 & 3.32 & -0.08 & 0.08 & 5.25 & -1.88 & -1.90 & 1.91 & -1.90 & 1.90 & 0.04 \\
\hline California & 1.88 & -0.12 & 3.36 & -0.12 & 0.12 & 5.25 & -1.46 & -1.72 & 2.40 & -1.72 & 1.72 & 0.94 \\
\hline Colorado & 2.00 & 0.00 & 3.24 & 0.00 & 0.00 & 5.25 & -1.77 & -1.80 & 1.86 & -1.80 & 1.80 & 0.09 \\
\hline Connecticut & 1.99 & -0.01 & 3.25 & -0.01 & 0.01 & 5.25 & -1.80 & -1.82 & 1.82 & -1.82 & 1.82 & 0.02 \\
\hline Delaware & 1.97 & -0.03 & 3.27 & -0.03 & 0.03 & 5.25 & -1.85 & -1.86 & 1.84 & -1.86 & 1.86 & -0.01 \\
\hline Washington DC & 1.92 & -0.08 & 3.32 & -0.08 & 0.08 & 5.25 & -1.91 & -1.91 & 1.89 & -1.91 & 1.91 & -0.02 \\
\hline Florida & 2.15 & 0.14 & 3.10 & 0.14 & -0.14 & 5.25 & -1.48 & -1.59 & 1.87 & -1.59 & 1.59 & 0.39 \\
\hline Georgia & 1.96 & -0.05 & 3.29 & -0.05 & 0.05 & 5.25 & -1.76 & -1.82 & 1.96 & -1.82 & 1.82 & 0.20 \\
\hline Hawaii & 1.89 & -0.12 & 3.36 & -0.12 & 0.12 & 5.25 & -1.93 & -1.94 & 1.94 & -1.94 & 1.94 & 0.00 \\
\hline Idaho & 1.89 & -0.11 & 3.35 & -0.11 & 0.11 & 5.25 & -1.93 & -1.94 & 1.92 & -1.94 & 1.94 & -0.01 \\
\hline Illinois & 2.06 & 0.05 & 3.19 & 0.05 & -0.05 & 5.25 & -1.62 & -1.70 & 1.87 & -1.70 & 1.70 & 0.25 \\
\hline Indiana & 2.05 & 0.04 & 3.20 & 0.04 & -0.04 & 5.25 & -1.71 & -1.75 & 1.82 & -1.75 & 1.75 & 0.11 \\
\hline lowa & 2.15 & 0.14 & 3.10 & 0.14 & -0.14 & 5.25 & -1.65 & -1.67 & 1.68 & -1.67 & 1.67 & 0.02 \\
\hline Kansas & 1.94 & -0.06 & 3.30 & -0.06 & 0.06 & 5.25 & -1.86 & -1.88 & 1.87 & -1.88 & 1.88 & 0.01 \\
\hline Kentucky & 1.96 & -0.04 & 3.28 & -0.04 & 0.04 & 5.25 & -1.82 & -1.85 & 1.88 & -1.85 & 1.85 & 0.07 \\
\hline Louisiana & 2.15 & 0.14 & 3.10 & 0.14 & -0.14 & 5.25 & -1.64 & -1.66 & 1.72 & -1.66 & 1.66 & 0.08 \\
\hline Maine & 1.86 & -0.14 & 3.38 & -0.14 & 0.14 & 5.25 & -1.95 & -1.96 & 1.93 & -1.96 & 1.96 & -0.03 \\
\hline Maryland & 2.00 & 0.00 & 3.25 & 0.00 & 0.00 & 5.25 & -1.76 & -1.80 & 1.87 & -1.80 & 1.80 & 0.10 \\
\hline Massachusetts & 1.72 & -0.28 & 3.53 & -0.28 & 0.28 & 5.25 & -2.02 & -2.07 & 2.15 & -2.07 & 2.07 & 0.13 \\
\hline Michigan & 2.03 & 0.03 & 3.22 & 0.03 & -0.03 & 5.25 & -1.68 & -1.75 & 1.87 & -1.75 & 1.75 & 0.19 \\
\hline Minnesota & 1.92 & -0.08 & 3.33 & -0.08 & 0.08 & 5.25 & -1.85 & -1.88 & 1.93 & -1.88 & 1.88 & 0.08 \\
\hline Mississippi & 1.99 & -0.01 & 3.25 & -0.01 & 0.01 & 5.25 & -1.81 & -1.83 & 1.85 & -1.83 & 1.83 & 0.04 \\
\hline Missouri & 2.15 & 0.14 & 3.10 & 0.14 & -0.14 & 5.25 & -1.62 & -1.66 & 1.72 & -1.66 & 1.66 & 0.10 \\
\hline Montana & 2.15 & 0.14 & 3.10 & 0.14 & -0.14 & 5.25 & -1.68 & -1.68 & 1.67 & -1.68 & 1.68 & -0.01 \\
\hline Nebraska & 1.93 & -0.08 & 3.32 & -0.08 & 0.08 & 5.25 & -1.89 & -1.90 & 1.85 & -1.90 & 1.90 & -0.04 \\
\hline Nevada & 2.15 & 0.14 & 3.10 & 0.14 & -0.14 & 5.25 & -1.66 & -1.67 & 1.69 & -1.67 & 1.67 & 0.03 \\
\hline New Hampshire & 1.99 & -0.01 & 3.25 & -0.01 & 0.01 & 5.25 & -1.83 & -1.84 & 1.80 & -1.84 & 1.84 & -0.03 \\
\hline New Jersey & 2.04 & 0.04 & 3.20 & 0.04 & -0.04 & 5.25 & -1.69 & -1.74 & 1.84 & -1.74 & 1.74 & 0.15 \\
\hline New Mexico & 1.98 & -0.02 & 3.26 & -0.02 & 0.02 & 5.25 & -1.83 & -1.84 & 1.84 & -1.84 & 1.84 & 0.01 \\
\hline New York & 1.93 & -0.08 & 3.32 & -0.08 & 0.08 & 5.25 & -1.65 & -1.79 & 2.11 & -1.79 & 1.79 & 0.45 \\
\hline North Carolina & 1.92 & -0.08 & 3.32 & -0.08 & 0.08 & 5.25 & -1.80 & -1.86 & 1.99 & -1.86 & 1.86 & 0.19 \\
\hline North Dakota & 2.03 & 0.02 & 3.22 & 0.02 & -0.02 & 5.25 & -1.80 & -1.81 & 1.76 & -1.81 & 1.81 & -0.05 \\
\hline Ohio & 2.02 & 0.02 & 3.22 & 0.02 & -0.02 & 5.25 & -1.67 & -1.74 & 1.90 & -1.74 & 1.74 & 0.23 \\
\hline Oklahoma & 1.95 & -0.05 & 3.30 & -0.05 & 0.05 & 5.25 & -1.84 & -1.87 & 1.89 & -1.87 & 1.87 & 0.05 \\
\hline Oregon & 1.85 & -0.16 & 3.40 & -0.16 & 0.16 & 5.25 & -1.94 & -1.97 & 1.99 & -1.97 & 1.97 & 0.05 \\
\hline Pennsylvania & 2.06 & 0.05 & 3.19 & 0.05 & -0.05 & 5.25 & -1.63 & -1.71 & 1.88 & -1.71 & 1.71 & 0.25 \\
\hline Rhode Island & 1.92 & -0.08 & 3.32 & -0.08 & 0.08 & 5.25 & -1.90 & -1.91 & 1.87 & -1.91 & 1.91 & -0.04 \\
\hline South Carolina & 1.92 & -0.08 & 3.32 & -0.08 & 0.08 & 5.25 & -1.86 & -1.89 & 1.93 & -1.89 & 1.89 & 0.08 \\
\hline South Dakota & 2.15 & 0.14 & 3.10 & 0.14 & -0.14 & 5.25 & -1.68 & -1.68 & 1.65 & -1.68 & 1.68 & -0.03 \\
\hline Tennessee & 1.96 & -0.05 & 3.29 & -0.05 & 0.05 & 5.25 & -1.80 & -1.84 & 1.92 & -1.84 & 1.84 & 0.12 \\
\hline Texas & 2.15 & 0.14 & 3.10 & 0.14 & -0.14 & 5.25 & -1.41 & -1.55 & 1.91 & -1.55 & 1.55 & 0.50 \\
\hline Utah & 1.92 & -0.08 & 3.32 & -0.08 & 0.08 & 5.25 & -1.88 & -1.90 & 1.91 & -1.90 & 1.90 & 0.03 \\
\hline Vermont & 1.91 & -0.09 & 3.33 & -0.09 & 0.09 & 5.25 & -1.91 & -1.92 & 1.85 & -1.92 & 1.92 & -0.06 \\
\hline Virginia & 1.97 & -0.04 & 3.28 & -0.04 & 0.04 & 5.25 & -1.77 & -1.82 & 1.93 & -1.82 & 1.82 & 0.16 \\
\hline Washington & 2.15 & 0.14 & 3.10 & 0.14 & -0.14 & 5.25 & -1.61 & -1.65 & 1.73 & -1.65 & 1.65 & 0.12 \\
\hline West Virginia & 2.01 & 0.01 & 3.24 & 0.01 & -0.01 & 5.25 & -1.81 & -1.82 & 1.82 & -1.82 & 1.82 & 0.01 \\
\hline Wisconsin & 1.94 & -0.06 & 3.31 & -0.06 & 0.06 & 5.25 & -1.82 & -1.86 & 1.89 & -1.86 & 1.86 & 0.07 \\
\hline Wyoming & 2.15 & 0.14 & 3.10 & 0.14 & -0.14 & 5.25 & -1.68 & -1.69 & 1.67 & -1.69 & 1.69 & -0.02 \\
\hline
\end{tabular}

Notes: CON stands for per capita consumption good, LAN for per capita land, PUB for per capita public good, HOW for per capita hours of work, POP for population, WEL for welfare measured by individual utility. 
Table 3 - Elasticities of Endogenous Variables with respect to Property Tax Rates

\begin{tabular}{|c|c|c|c|c|c|c|c|c|c|c|c|c|}
\hline \multirow[b]{2}{*}{ STATE } & \multicolumn{6}{|c|}{ NATIONWIDE PROPERTY TAX RATES } & \multicolumn{6}{|c|}{ STATE-LEVEL PROPERTY TAX RATES } \\
\hline & CON & LAN & PUB & HOW & POP & WEL & CON & LAN & PUB & HOW & POP & WEL \\
\hline Alabama & 0.42 & -0.25 & 0.68 & 0.42 & 0.25 & 0.43 & 0.01 & -0.66 & 0.67 & 0.01 & 0.66 & 0.01 \\
\hline Alaska & 0.42 & 0.05 & 0.38 & 0.42 & -0.05 & 0.43 & 0.00 & -0.36 & 0.36 & 0.00 & 0.36 & -0.01 \\
\hline Arizona & 0.42 & -0.12 & 0.55 & 0.42 & 0.12 & 0.43 & 0.01 & -0.53 & 0.54 & 0.01 & 0.53 & 0.02 \\
\hline Arkansas & 0.42 & -0.14 & 0.57 & 0.42 & 0.14 & 0.43 & 0.01 & -0.55 & 0.55 & 0.01 & 0.55 & 0.00 \\
\hline California & 0.42 & -0.13 & 0.56 & 0.42 & 0.13 & 0.43 & 0.07 & -0.48 & 0.60 & 0.07 & 0.48 & 0.12 \\
\hline Colorado & 0.42 & -0.10 & 0.53 & 0.42 & 0.10 & 0.43 & 0.01 & -0.50 & 0.51 & 0.01 & 0.50 & 0.01 \\
\hline Connecticut & 0.42 & 0.11 & 0.32 & 0.42 & -0.11 & 0.43 & 0.00 & -0.30 & 0.30 & 0.00 & 0.30 & 0.00 \\
\hline Delaware & 0.42 & -0.18 & 0.61 & 0.42 & 0.18 & 0.43 & 0.00 & -0.59 & 0.59 & 0.00 & 0.59 & 0.00 \\
\hline Washington DC & 0.42 & -0.19 & 0.62 & 0.42 & 0.19 & 0.43 & 0.00 & -0.60 & 0.60 & 0.00 & 0.60 & -0.01 \\
\hline Florida & 0.42 & -0.02 & 0.45 & 0.42 & 0.02 & 0.43 & 0.03 & -0.41 & 0.45 & 0.03 & 0.41 & 0.04 \\
\hline Georgia & 0.42 & -0.03 & 0.46 & 0.42 & 0.03 & 0.43 & 0.01 & -0.43 & 0.45 & 0.01 & 0.43 & 0.02 \\
\hline Hawaii & 0.42 & -0.31 & 0.74 & 0.42 & 0.31 & 0.43 & 0.00 & -0.73 & 0.72 & 0.00 & 0.73 & 0.00 \\
\hline Idaho & 0.42 & -0.06 & 0.49 & 0.42 & 0.06 & 0.43 & 0.00 & -0.47 & 0.47 & 0.00 & 0.47 & 0.00 \\
\hline Illinois & 0.42 & 0.13 & 0.30 & 0.42 & -0.13 & 0.43 & 0.01 & -0.27 & 0.29 & 0.01 & 0.27 & 0.02 \\
\hline Indiana & 0.42 & 0.03 & 0.40 & 0.42 & -0.03 & 0.43 & 0.01 & -0.38 & 0.39 & 0.01 & 0.38 & 0.01 \\
\hline lowa & 0.42 & 0.09 & 0.34 & 0.42 & -0.09 & 0.43 & 0.00 & -0.33 & 0.33 & 0.00 & 0.33 & 0.00 \\
\hline Kansas & 0.42 & 0.08 & 0.34 & 0.42 & -0.08 & 0.43 & 0.00 & -0.33 & 0.33 & 0.00 & 0.33 & 0.00 \\
\hline Kentucky & 0.42 & -0.05 & 0.48 & 0.42 & 0.05 & 0.43 & 0.01 & -0.46 & 0.47 & 0.01 & 0.46 & 0.01 \\
\hline Louisiana & 0.42 & -0.39 & 0.82 & 0.42 & 0.39 & 0.43 & 0.01 & -0.79 & 0.81 & 0.01 & 0.79 & 0.02 \\
\hline Maine & 0.42 & 0.04 & 0.39 & 0.42 & -0.04 & 0.43 & 0.00 & -0.37 & 0.36 & 0.00 & 0.37 & -0.01 \\
\hline Maryland & 0.42 & -0.05 & 0.48 & 0.42 & 0.05 & 0.43 & 0.01 & -0.46 & 0.47 & 0.01 & 0.46 & 0.01 \\
\hline Massachusetts & 0.42 & 0.01 & 0.42 & 0.42 & -0.01 & 0.43 & 0.01 & -0.39 & 0.40 & 0.01 & 0.39 & 0.01 \\
\hline Michigan & 0.42 & 0.11 & 0.32 & 0.42 & -0.11 & 0.43 & 0.01 & -0.30 & 0.31 & 0.01 & 0.30 & 0.01 \\
\hline Minnesota & 0.42 & 0.01 & 0.42 & 0.42 & -0.01 & 0.43 & 0.01 & -0.40 & 0.40 & 0.01 & 0.40 & 0.01 \\
\hline Mississippi & 0.42 & -0.14 & 0.57 & 0.42 & 0.14 & 0.43 & 0.01 & -0.55 & 0.56 & 0.01 & 0.55 & 0.00 \\
\hline Missouri & 0.42 & 0.00 & 0.43 & 0.42 & 0.00 & 0.43 & 0.01 & -0.41 & 0.42 & 0.01 & 0.41 & 0.01 \\
\hline Montana & 0.42 & -0.01 & 0.44 & 0.42 & 0.01 & 0.43 & 0.00 & -0.42 & 0.42 & 0.00 & 0.42 & 0.00 \\
\hline Nebraska & 0.42 & 0.16 & 0.27 & 0.42 & -0.16 & 0.43 & 0.00 & -0.26 & 0.25 & 0.00 & 0.26 & -0.01 \\
\hline Nevada & 0.42 & -0.12 & 0.55 & 0.42 & 0.12 & 0.43 & 0.00 & -0.53 & 0.53 & 0.00 & 0.53 & 0.00 \\
\hline New Hampshire & 0.42 & 0.15 & 0.28 & 0.42 & -0.15 & 0.43 & 0.00 & -0.27 & 0.26 & 0.00 & 0.27 & -0.01 \\
\hline New Jersey & 0.42 & 0.14 & 0.29 & 0.42 & -0.14 & 0.43 & 0.01 & -0.26 & 0.27 & 0.01 & 0.26 & 0.01 \\
\hline New Mexico & 0.42 & -0.13 & 0.56 & 0.42 & 0.13 & 0.43 & 0.00 & -0.54 & 0.54 & 0.00 & 0.54 & 0.00 \\
\hline New York & 0.42 & 0.06 & 0.37 & 0.42 & -0.06 & 0.43 & 0.02 & -0.33 & 0.37 & 0.02 & 0.33 & 0.04 \\
\hline North Carolina & 0.42 & -0.03 & 0.46 & 0.42 & 0.03 & 0.43 & 0.01 & -0.43 & 0.45 & 0.01 & 0.43 & 0.02 \\
\hline North Dakota & 0.42 & 0.11 & 0.32 & 0.42 & -0.11 & 0.43 & 0.00 & -0.30 & 0.30 & 0.00 & 0.30 & -0.01 \\
\hline Ohio & 0.42 & 0.10 & 0.33 & 0.42 & -0.10 & 0.43 & 0.01 & -0.31 & 0.32 & 0.01 & 0.31 & 0.02 \\
\hline Oklahoma & 0.42 & -0.05 & 0.48 & 0.42 & 0.05 & 0.43 & 0.01 & -0.46 & 0.46 & 0.01 & 0.46 & 0.00 \\
\hline Oregon & 0.42 & -0.02 & 0.45 & 0.42 & 0.02 & 0.43 & 0.01 & -0.43 & 0.43 & 0.01 & 0.43 & 0.00 \\
\hline Pennsylvania & 0.42 & 0.11 & 0.32 & 0.42 & -0.11 & 0.43 & 0.01 & -0.29 & 0.31 & 0.01 & 0.29 & 0.02 \\
\hline Rhode Island & 0.42 & 0.07 & 0.36 & 0.42 & -0.07 & 0.43 & 0.00 & -0.35 & 0.34 & 0.00 & 0.35 & -0.01 \\
\hline South Carolina & 0.42 & -0.10 & 0.53 & 0.42 & 0.10 & 0.43 & 0.01 & -0.51 & 0.52 & 0.01 & 0.51 & 0.01 \\
\hline South Dakota & 0.42 & 0.10 & 0.33 & 0.42 & -0.10 & 0.43 & 0.00 & -0.32 & 0.31 & 0.00 & 0.32 & -0.01 \\
\hline Tennessee & 0.42 & -0.05 & 0.48 & 0.42 & 0.05 & 0.43 & 0.01 & -0.46 & 0.47 & 0.01 & 0.46 & 0.01 \\
\hline Texas & 0.42 & 0.17 & 0.26 & 0.42 & -0.17 & 0.43 & 0.02 & -0.23 & 0.26 & 0.02 & 0.23 & 0.03 \\
\hline Utah & 0.42 & -0.10 & 0.53 & 0.42 & 0.10 & 0.43 & 0.00 & -0.51 & 0.51 & 0.00 & 0.51 & 0.00 \\
\hline Vermont & 0.42 & 0.13 & 0.30 & 0.42 & -0.13 & 0.43 & 0.00 & -0.28 & 0.27 & 0.00 & 0.28 & -0.01 \\
\hline Virginia & 0.42 & -0.06 & 0.49 & 0.42 & 0.06 & 0.43 & 0.01 & -0.47 & 0.48 & 0.01 & 0.47 & 0.02 \\
\hline Washington & 0.42 & -0.01 & 0.44 & 0.42 & 0.01 & 0.43 & 0.01 & -0.42 & 0.43 & 0.01 & 0.42 & 0.01 \\
\hline West Virginia & 0.42 & -0.15 & 0.58 & 0.42 & 0.15 & 0.43 & 0.00 & -0.56 & 0.56 & 0.00 & 0.56 & 0.00 \\
\hline Wisconsin & 0.42 & 0.15 & 0.28 & 0.42 & -0.15 & 0.43 & 0.00 & -0.26 & 0.26 & 0.00 & 0.26 & 0.00 \\
\hline Wyoming & 0.42 & -0.13 & 0.56 & 0.42 & 0.13 & 0.43 & 0.00 & -0.54 & 0.54 & 0.00 & 0.54 & -0.01 \\
\hline
\end{tabular}

Notes: CON stands for per capita consumption good, LAN for per capita land, PUB for per capita public good, HOW for per capita hours of work, POP for population, WEL for welfare measured by individual utility. 
Table 4 - Elasticities of Endogenous Variables with respect to Sales Tax Rates

\begin{tabular}{|c|c|c|c|c|c|c|c|c|c|c|c|c|}
\hline \multirow[b]{2}{*}{ STATE } & \multicolumn{6}{|c|}{ NATIONWIDE SALES TAX RATES } & \multicolumn{6}{|c|}{ STATE-LEVEL SALES TAX RATES } \\
\hline & CON & LAN & PUB & HOW & POP & WEL & CON & LAN & PUB & HOW & POP & WEL \\
\hline Alabama & -0.78 & 0.00 & 0.52 & 0.00 & 0.00 & -0.26 & -0.95 & 0.00 & 0.95 & 0.00 & 0.00 & 0.00 \\
\hline Alaska & -0.82 & 0.00 & 0.56 & 0.00 & 0.00 & -0.26 & -0.99 & 0.00 & 0.98 & 0.00 & 0.00 & -0.01 \\
\hline Arizona & -0.77 & 0.00 & 0.51 & 0.00 & 0.00 & -0.26 & -0.94 & 0.00 & 0.94 & 0.00 & 0.00 & 0.00 \\
\hline Arkansas & -0.76 & 0.00 & 0.50 & 0.00 & 0.00 & -0.26 & -0.94 & 0.00 & 0.93 & 0.00 & 0.00 & -0.01 \\
\hline California & -0.76 & 0.00 & 0.50 & 0.00 & 0.00 & -0.26 & -0.92 & 0.00 & 0.95 & 0.00 & 0.00 & 0.03 \\
\hline Colorado & -0.79 & 0.00 & 0.53 & 0.00 & 0.00 & -0.26 & -0.96 & 0.00 & 0.96 & 0.00 & 0.00 & 0.00 \\
\hline Connecticut & -0.76 & 0.00 & 0.50 & 0.00 & 0.00 & -0.26 & -0.94 & 0.00 & 0.92 & 0.00 & 0.00 & -0.01 \\
\hline Delaware & -0.82 & 0.00 & 0.56 & 0.00 & 0.00 & -0.26 & -0.99 & 0.00 & 0.99 & 0.00 & 0.00 & -0.01 \\
\hline Washington DC & -0.76 & 0.00 & 0.51 & 0.00 & 0.00 & -0.26 & -0.94 & 0.00 & 0.93 & 0.00 & 0.00 & -0.01 \\
\hline Florida & -0.76 & 0.00 & 0.50 & 0.00 & 0.00 & -0.26 & -0.93 & 0.00 & 0.94 & 0.00 & 0.00 & 0.01 \\
\hline Georgia & -0.78 & 0.00 & 0.52 & 0.00 & 0.00 & -0.26 & -0.95 & 0.00 & 0.95 & 0.00 & 0.00 & 0.00 \\
\hline Hawaii & -0.78 & 0.00 & 0.52 & 0.00 & 0.00 & -0.26 & -0.96 & 0.00 & 0.95 & 0.00 & 0.00 & -0.01 \\
\hline Idaho & -0.76 & 0.00 & 0.50 & 0.00 & 0.00 & -0.26 & -0.94 & 0.00 & 0.93 & 0.00 & 0.00 & -0.01 \\
\hline Illinois & -0.76 & 0.00 & 0.50 & 0.00 & 0.00 & -0.26 & -0.93 & 0.00 & 0.93 & 0.00 & 0.00 & 0.00 \\
\hline Indiana & -0.76 & 0.00 & 0.50 & 0.00 & 0.00 & -0.26 & -0.94 & 0.00 & 0.93 & 0.00 & 0.00 & 0.00 \\
\hline lowa & -0.77 & 0.00 & 0.51 & 0.00 & 0.00 & -0.26 & -0.95 & 0.00 & 0.94 & 0.00 & 0.00 & -0.01 \\
\hline Kansas & -0.77 & 0.00 & 0.51 & 0.00 & 0.00 & -0.26 & -0.94 & 0.00 & 0.93 & 0.00 & 0.00 & -0.01 \\
\hline Kentucky & -0.76 & 0.00 & 0.50 & 0.00 & 0.00 & -0.26 & -0.94 & 0.00 & 0.93 & 0.00 & 0.00 & -0.01 \\
\hline Louisiana & -0.78 & 0.00 & 0.52 & 0.00 & 0.00 & -0.26 & -0.95 & 0.00 & 0.95 & 0.00 & 0.00 & 0.00 \\
\hline Maine & -0.77 & 0.00 & 0.51 & 0.00 & 0.00 & -0.26 & -0.95 & 0.00 & 0.93 & 0.00 & 0.00 & -0.01 \\
\hline Maryland & -0.77 & 0.00 & 0.51 & 0.00 & 0.00 & -0.26 & -0.94 & 0.00 & 0.94 & 0.00 & 0.00 & 0.00 \\
\hline Massachusetts & -0.77 & 0.00 & 0.51 & 0.00 & 0.00 & -0.26 & -0.94 & 0.00 & 0.94 & 0.00 & 0.00 & -0.01 \\
\hline Michigan & -0.76 & 0.00 & 0.50 & 0.00 & 0.00 & -0.26 & -0.93 & 0.00 & 0.93 & 0.00 & 0.00 & 0.00 \\
\hline Minnesota & -0.76 & 0.00 & 0.50 & 0.00 & 0.00 & -0.26 & -0.93 & 0.00 & 0.92 & 0.00 & 0.00 & -0.01 \\
\hline Mississippi & -0.75 & 0.00 & 0.49 & 0.00 & 0.00 & -0.26 & -0.93 & 0.00 & 0.92 & 0.00 & 0.00 & -0.01 \\
\hline Missouri & -0.78 & 0.00 & 0.52 & 0.00 & 0.00 & -0.26 & -0.95 & 0.00 & 0.95 & 0.00 & 0.00 & 0.00 \\
\hline Montana & -0.82 & 0.00 & 0.56 & 0.00 & 0.00 & -0.26 & -0.99 & 0.00 & 0.99 & 0.00 & 0.00 & -0.01 \\
\hline Nebraska & -0.77 & 0.00 & 0.51 & 0.00 & 0.00 & -0.26 & -0.94 & 0.00 & 0.92 & 0.00 & 0.00 & -0.02 \\
\hline Nevada & -0.76 & 0.00 & 0.50 & 0.00 & 0.00 & -0.26 & -0.93 & 0.00 & 0.93 & 0.00 & 0.00 & 0.00 \\
\hline New Hampshire & -0.82 & 0.00 & 0.56 & 0.00 & 0.00 & -0.26 & -0.99 & 0.00 & 0.98 & 0.00 & 0.00 & -0.02 \\
\hline New Jersey & -0.75 & 0.00 & 0.49 & 0.00 & 0.00 & -0.26 & -0.93 & 0.00 & 0.92 & 0.00 & 0.00 & -0.01 \\
\hline New Mexico & -0.77 & 0.00 & 0.51 & 0.00 & 0.00 & -0.26 & -0.95 & 0.00 & 0.94 & 0.00 & 0.00 & -0.01 \\
\hline New York & -0.78 & 0.00 & 0.52 & 0.00 & 0.00 & -0.26 & -0.95 & 0.00 & 0.95 & 0.00 & 0.00 & 0.01 \\
\hline North Carolina & -0.78 & 0.00 & 0.52 & 0.00 & 0.00 & -0.26 & -0.95 & 0.00 & 0.95 & 0.00 & 0.00 & 0.00 \\
\hline North Dakota & -0.77 & 0.00 & 0.51 & 0.00 & 0.00 & -0.26 & -0.95 & 0.00 & 0.93 & 0.00 & 0.00 & -0.01 \\
\hline Ohio & -0.77 & 0.00 & 0.51 & 0.00 & 0.00 & -0.26 & -0.94 & 0.00 & 0.94 & 0.00 & 0.00 & 0.00 \\
\hline Oklahoma & -0.78 & 0.00 & 0.52 & 0.00 & 0.00 & -0.26 & -0.95 & 0.00 & 0.94 & 0.00 & 0.00 & -0.01 \\
\hline Oregon & -0.82 & 0.00 & 0.56 & 0.00 & 0.00 & -0.26 & -0.99 & 0.00 & 0.98 & 0.00 & 0.00 & -0.01 \\
\hline Pennsylvania & -0.76 & 0.00 & 0.50 & 0.00 & 0.00 & -0.26 & -0.93 & 0.00 & 0.93 & 0.00 & 0.00 & 0.00 \\
\hline Rhode Island & -0.75 & 0.00 & 0.49 & 0.00 & 0.00 & -0.26 & -0.93 & 0.00 & 0.92 & 0.00 & 0.00 & -0.01 \\
\hline South Carolina & -0.77 & 0.00 & 0.51 & 0.00 & 0.00 & -0.26 & -0.95 & 0.00 & 0.94 & 0.00 & 0.00 & -0.01 \\
\hline South Dakota & -0.78 & 0.00 & 0.52 & 0.00 & 0.00 & -0.26 & -0.96 & 0.00 & 0.95 & 0.00 & 0.00 & -0.01 \\
\hline Tennessee & -0.75 & 0.00 & 0.49 & 0.00 & 0.00 & -0.26 & -0.93 & 0.00 & 0.92 & 0.00 & 0.00 & 0.00 \\
\hline Texas & -0.76 & 0.00 & 0.50 & 0.00 & 0.00 & -0.26 & -0.92 & 0.00 & 0.94 & 0.00 & 0.00 & 0.01 \\
\hline Utah & -0.77 & 0.00 & 0.51 & 0.00 & 0.00 & -0.26 & -0.95 & 0.00 & 0.94 & 0.00 & 0.00 & -0.01 \\
\hline Vermont & -0.76 & 0.00 & 0.50 & 0.00 & 0.00 & -0.26 & -0.94 & 0.00 & 0.92 & 0.00 & 0.00 & -0.02 \\
\hline Virginia & -0.78 & 0.00 & 0.52 & 0.00 & 0.00 & -0.26 & -0.95 & 0.00 & 0.95 & 0.00 & 0.00 & 0.00 \\
\hline Washington & -0.76 & 0.00 & 0.50 & 0.00 & 0.00 & -0.26 & -0.93 & 0.00 & 0.93 & 0.00 & 0.00 & 0.00 \\
\hline West Virginia & -0.76 & 0.00 & 0.50 & 0.00 & 0.00 & -0.26 & -0.94 & 0.00 & 0.93 & 0.00 & 0.00 & -0.01 \\
\hline Wisconsin & -0.77 & 0.00 & 0.51 & 0.00 & 0.00 & -0.26 & -0.94 & 0.00 & 0.93 & 0.00 & 0.00 & -0.01 \\
\hline Wyoming & -0.78 & 0.00 & 0.52 & 0.00 & 0.00 & -0.26 & -0.96 & 0.00 & 0.95 & 0.00 & 0.00 & -0.01 \\
\hline
\end{tabular}

Notes: CON stands for per capita consumption good, LAN for per capita land, PUB for per capita public good, HOW for per capita hours of work, POP for population, WEL for welfare measured by individual utility. 


\section{Figure 1 - Descriptive Statistics}

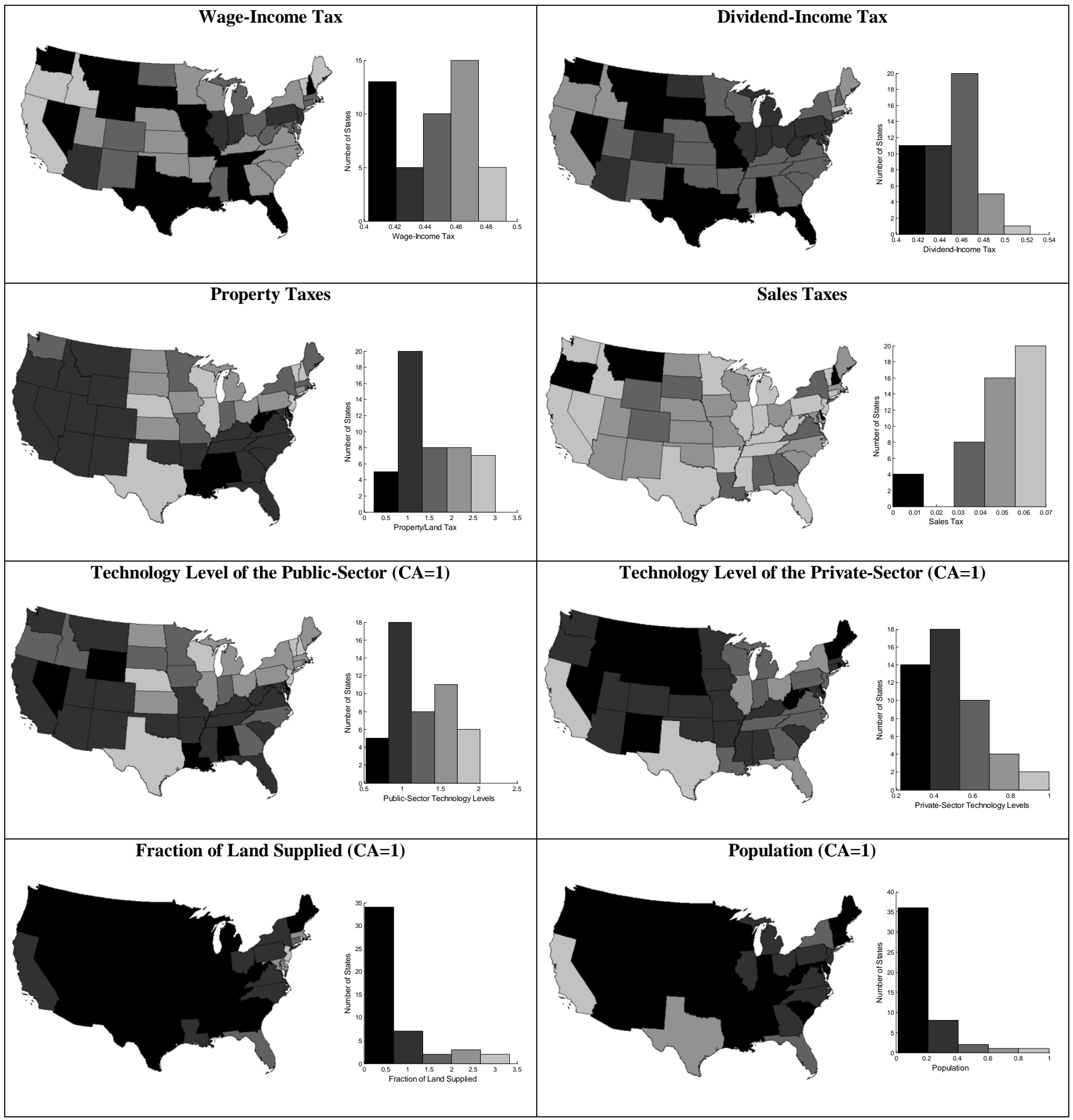


Figure 2 - Model versus Data

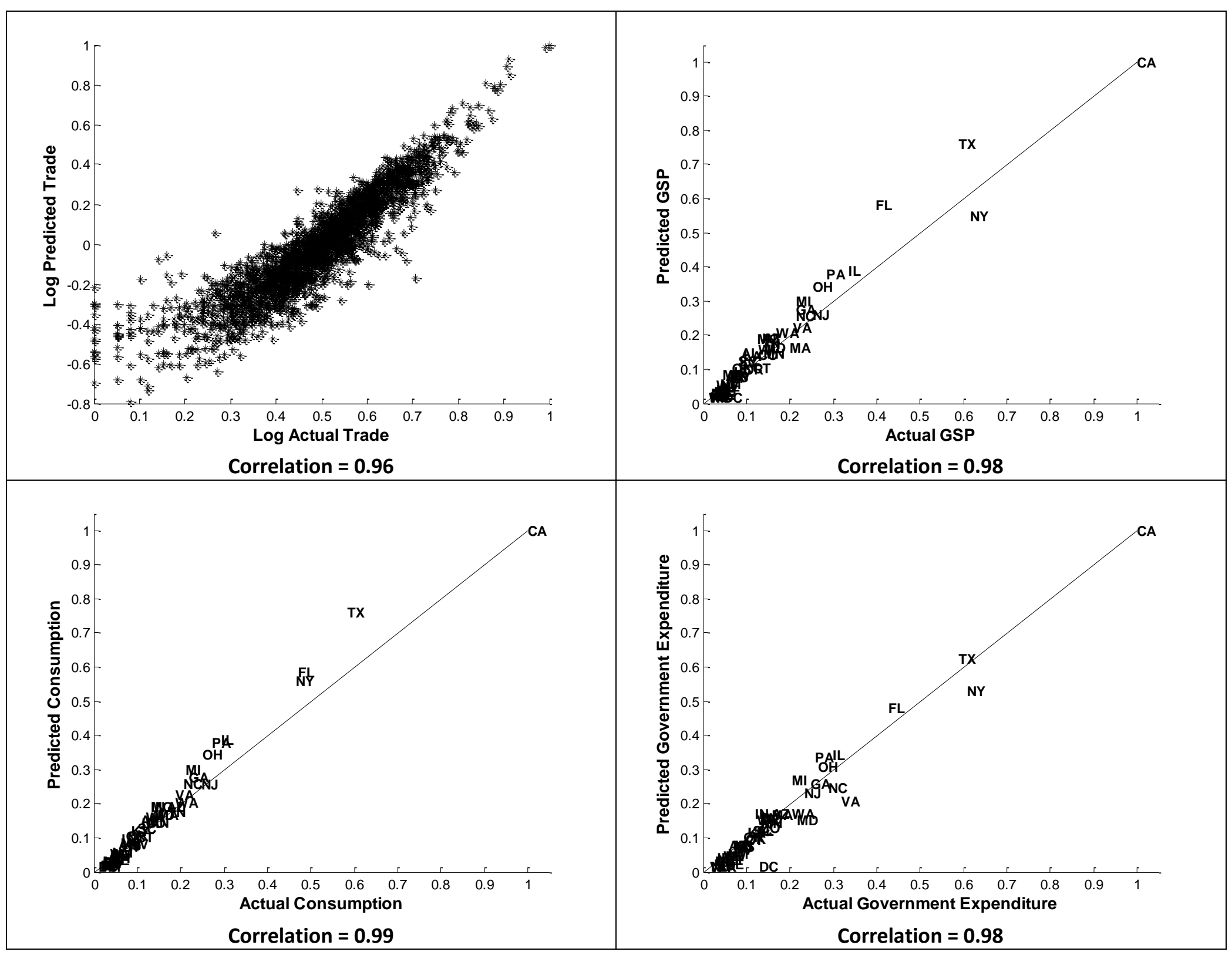




\section{Figure 3 - Elasticities of National Variables with respect to Tax Rates}

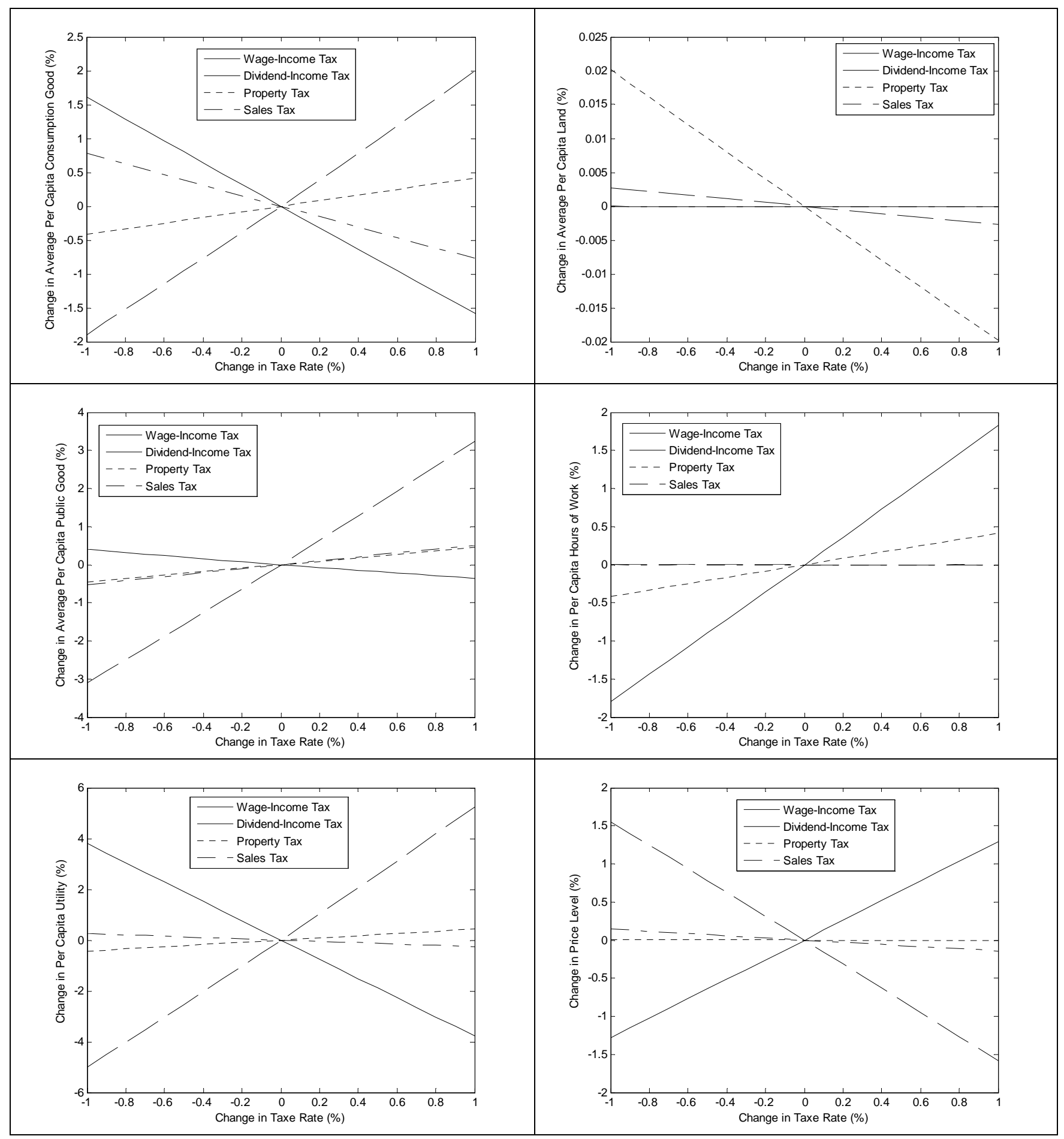

Wage-Income Tax — - Diwidend-Income Tax -.-.- Property Tax - - - Sales Tax 
Figure 4 - Elasticities of National Variables with respect to Tax Rates $(g=0)$

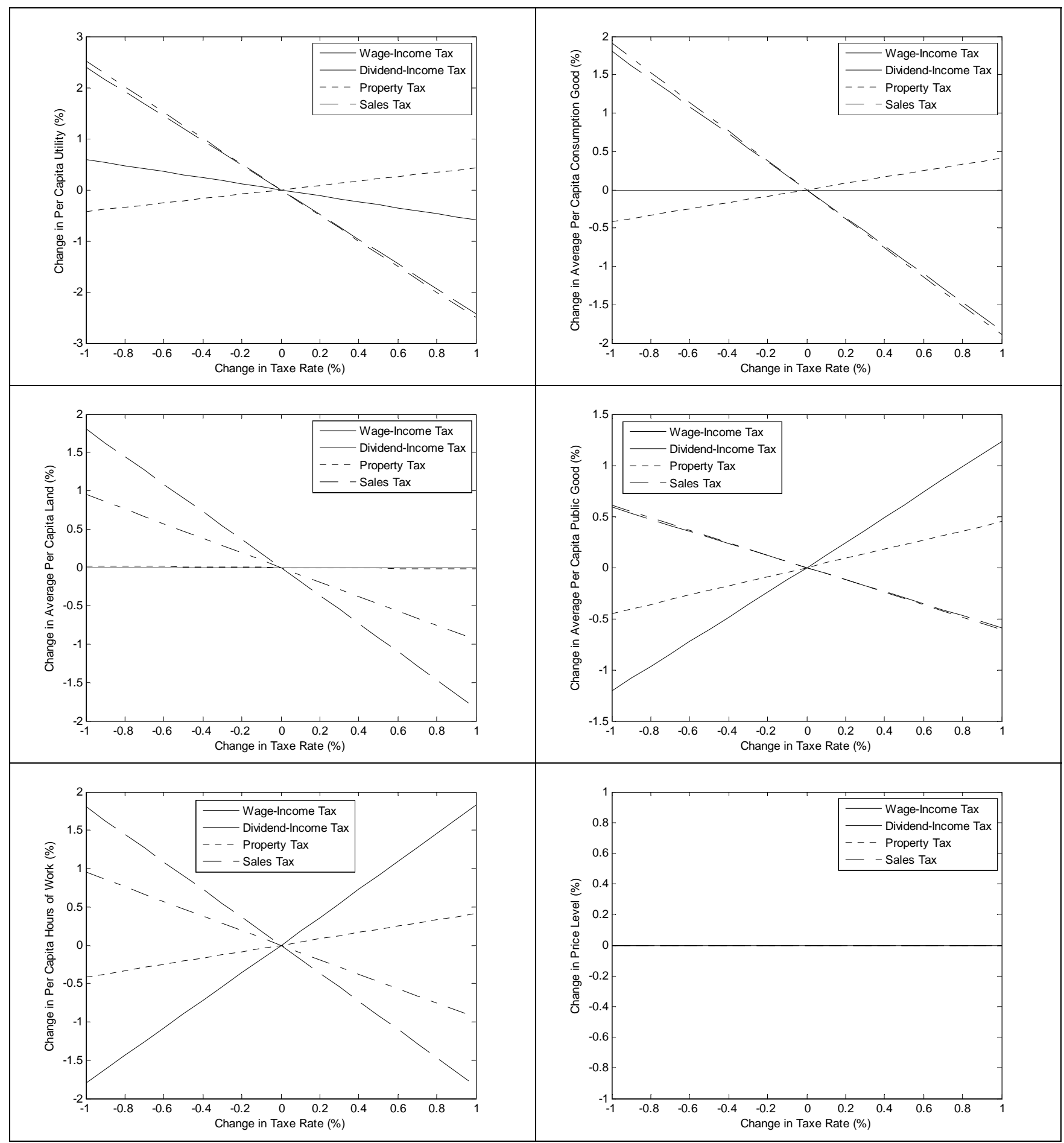

Wage-Income Tax — - Diwidend-Income Tax -.-.- Property Tax - - - Sales Tax 
Figure 5 - Elasticities of Endogenous Variables with respect to Nationwide Wage-Income Tax Rates

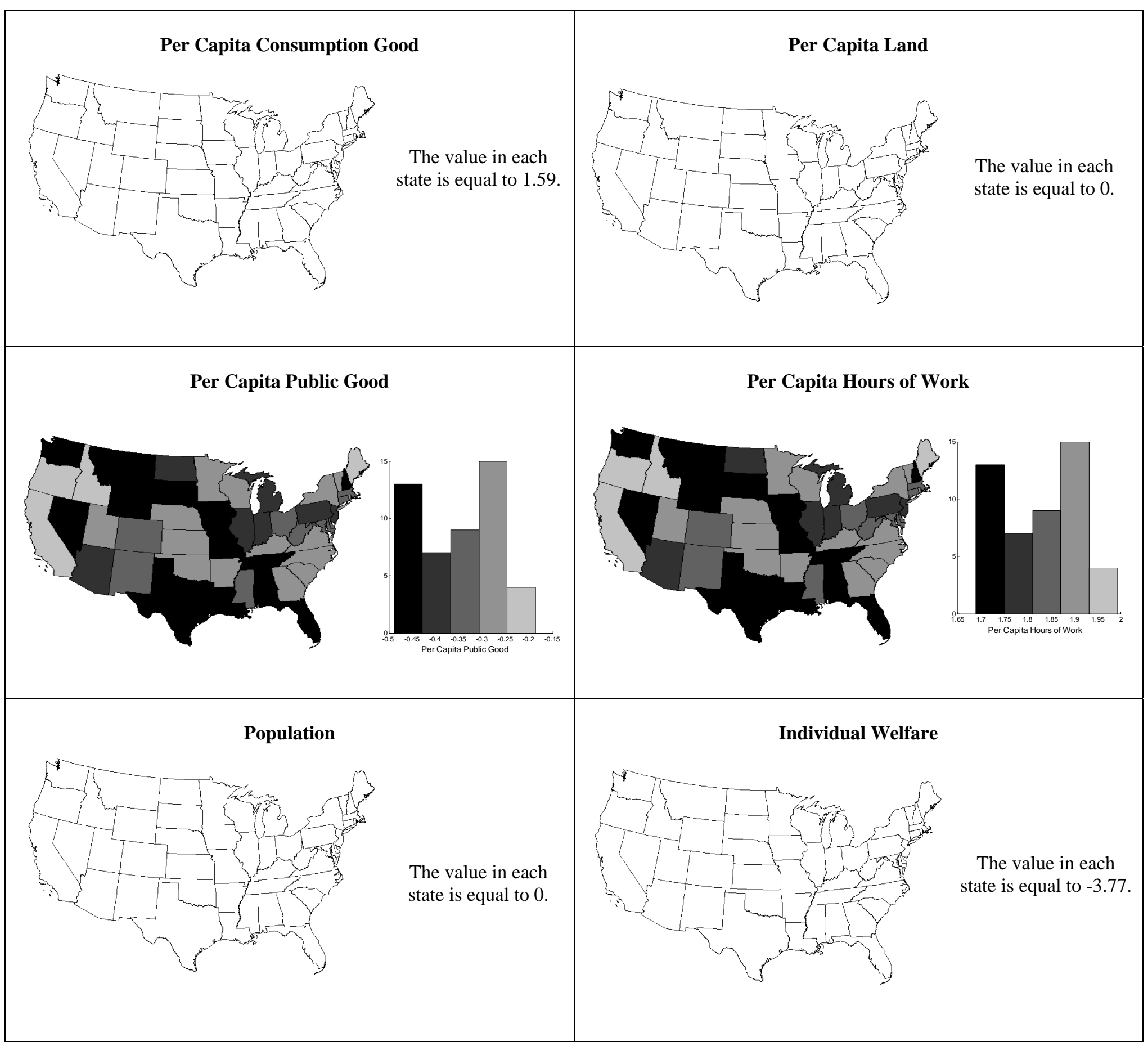


Figure 6 - Elasticities of Endogenous Variables with respect to Nationwide Dividend-Income Tax Rates

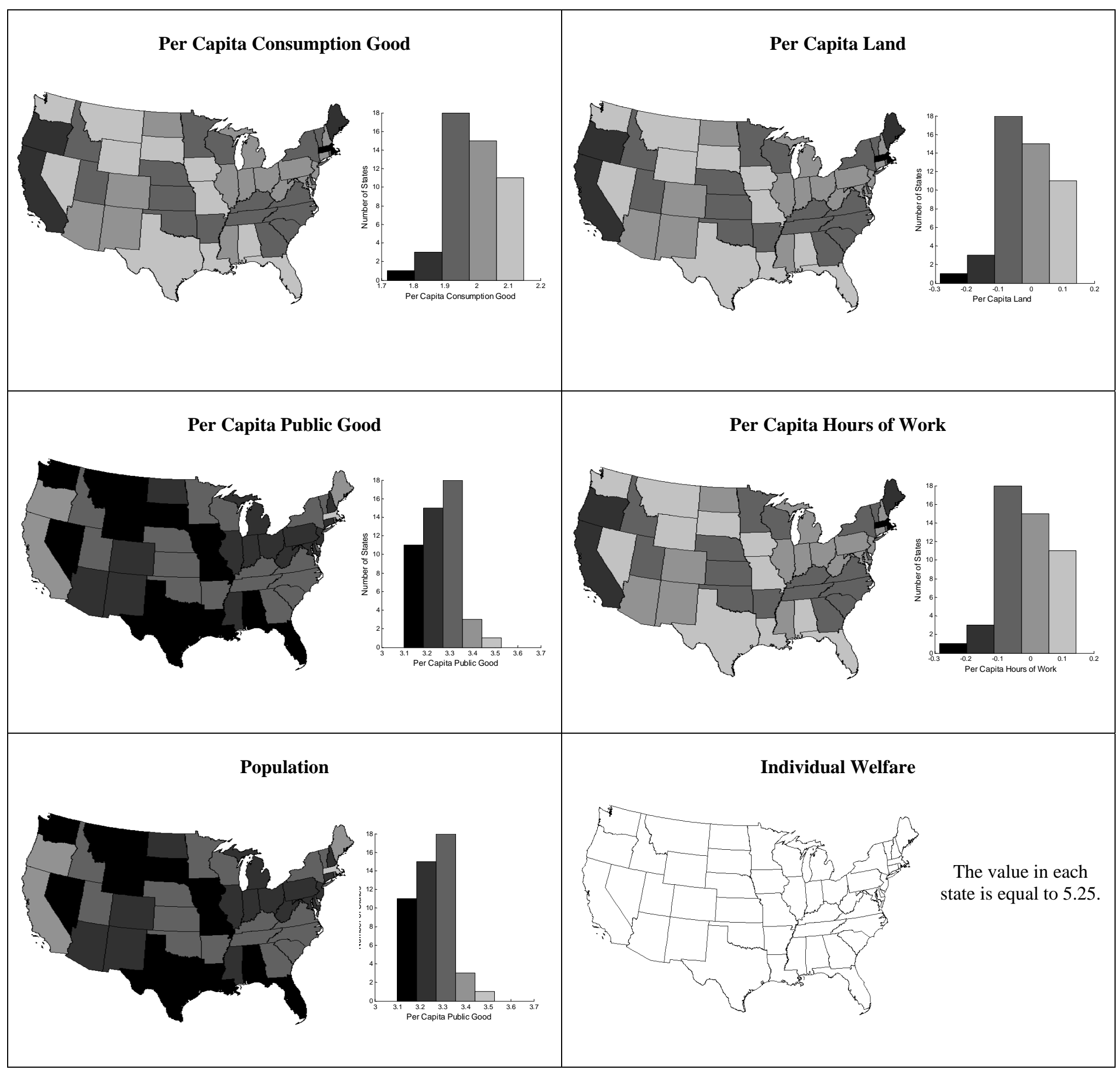


Figure 7 - Elasticities of Endogenous Variables with respect to Nationwide Property Tax Rates

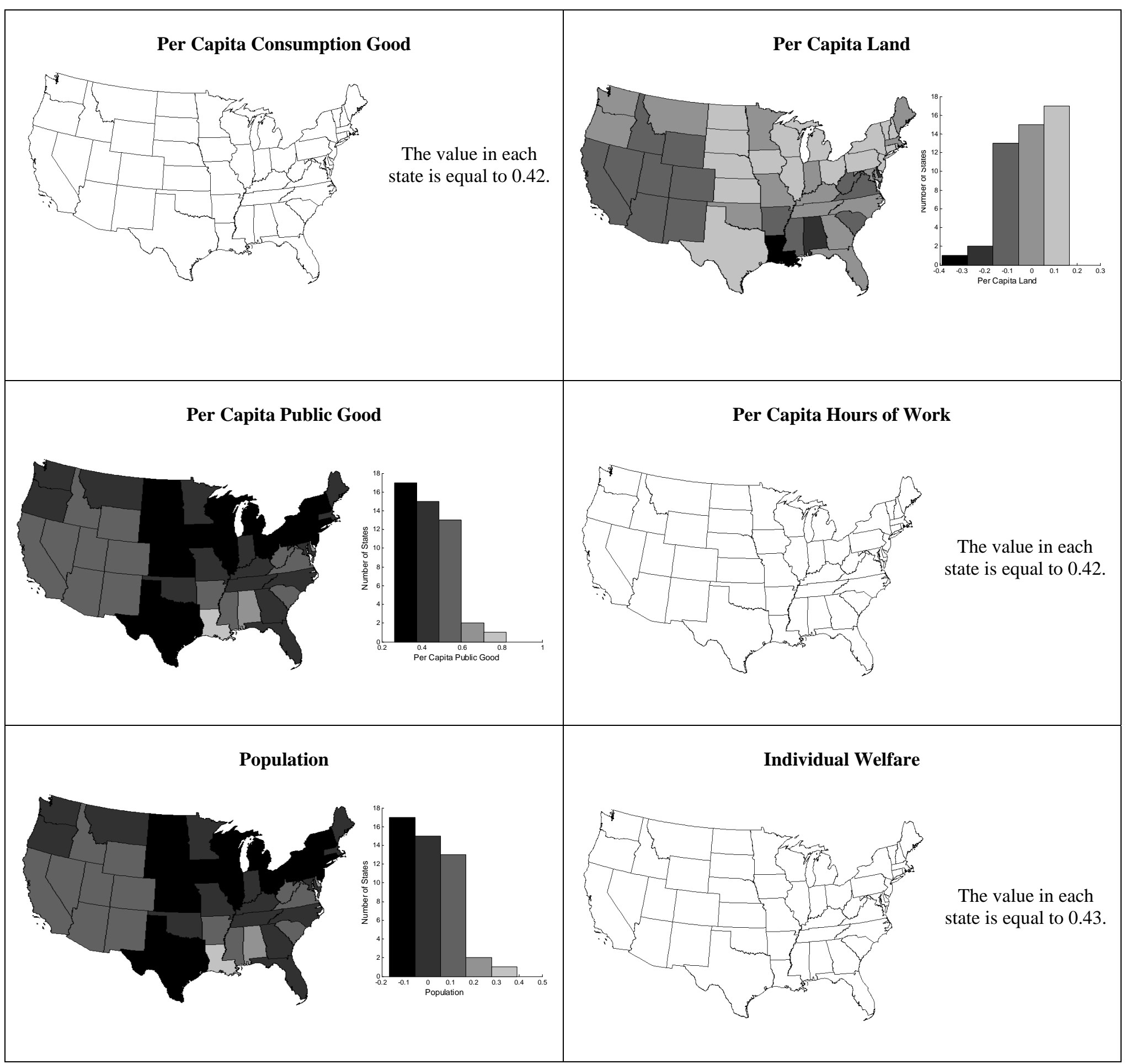


Figure 8 - Elasticities of Endogenous Variables with respect to Nationwide Sales Tax Rates

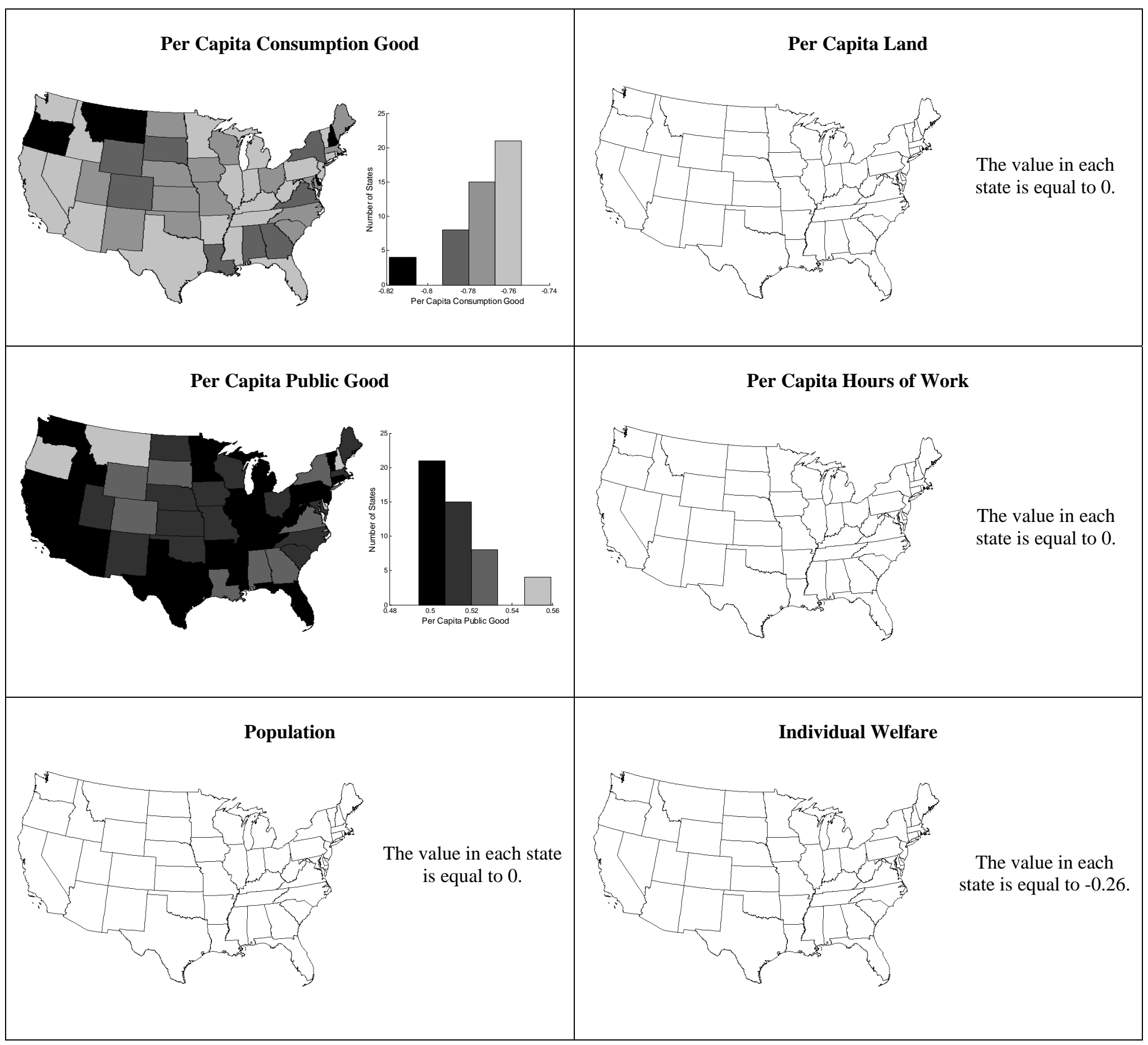


Figure 9 - Elasticities of Endogenous Variables with respect to State-Level Wage-Income Tax Rates

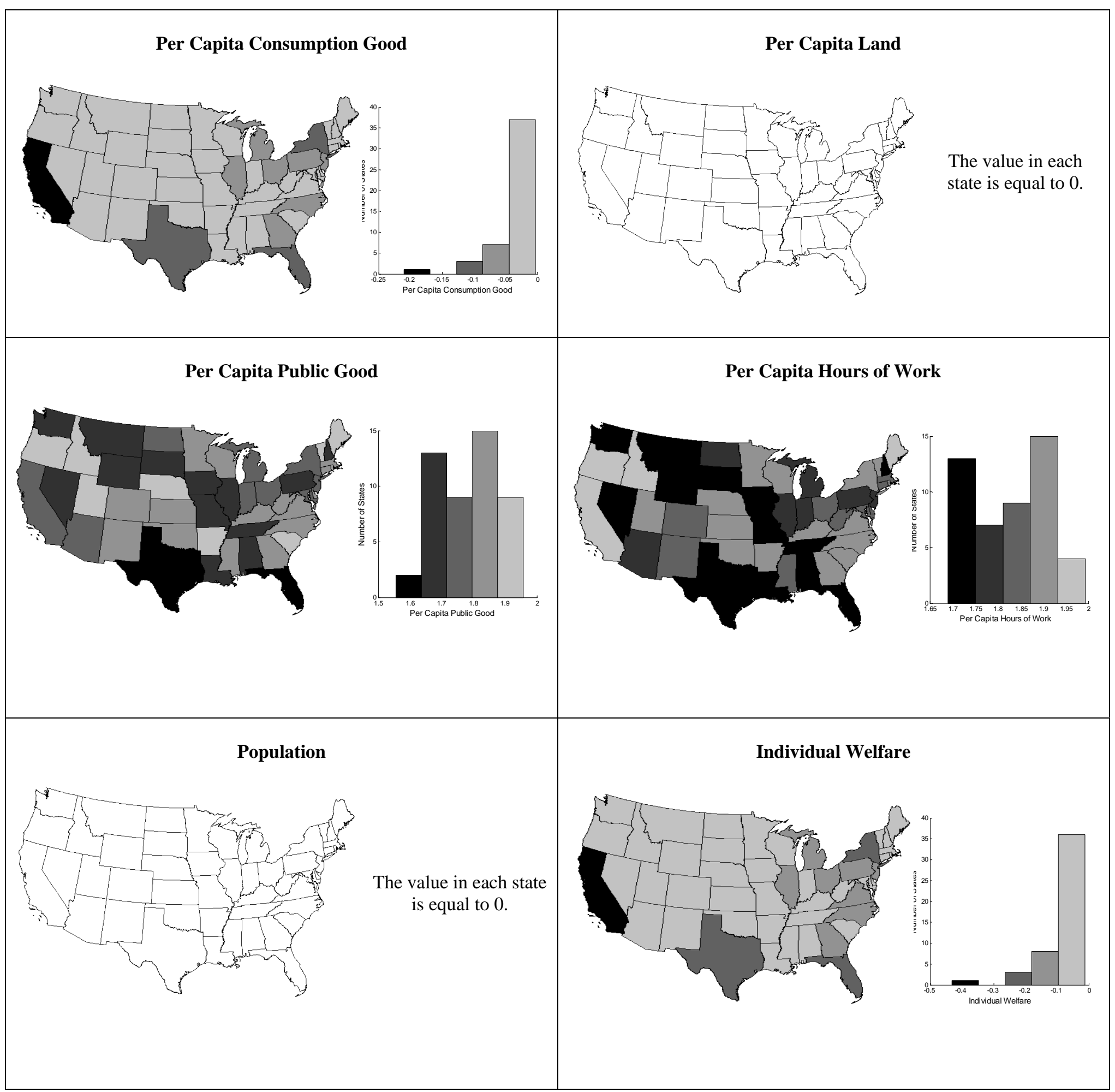


Figure 10 - Elasticities of Endogenous Variables with respect to State-Level Dividend-Income Tax Rates

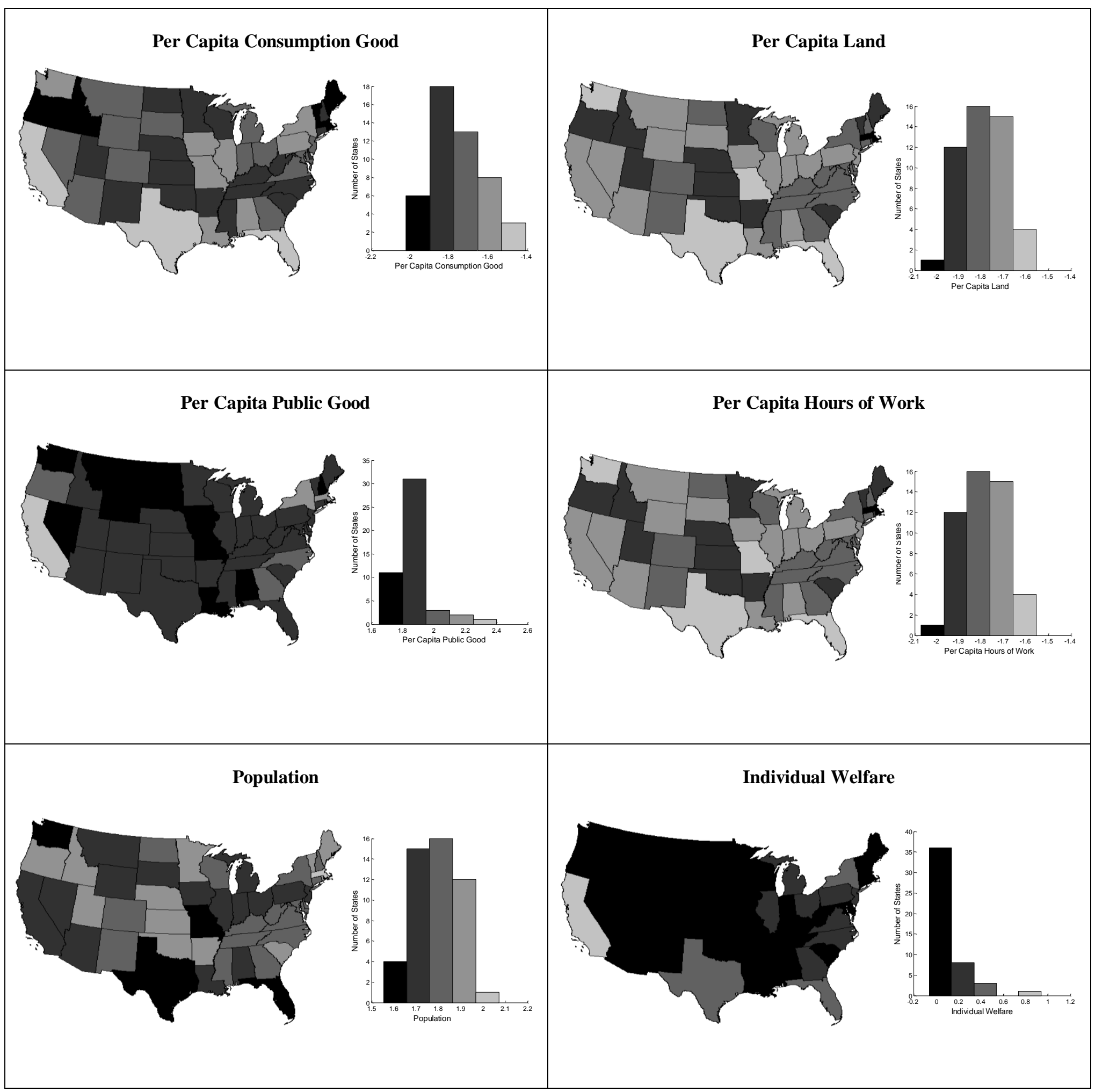


Figure 11 - Elasticities of Endogenous Variables with respect to State-Level Property Tax Rates

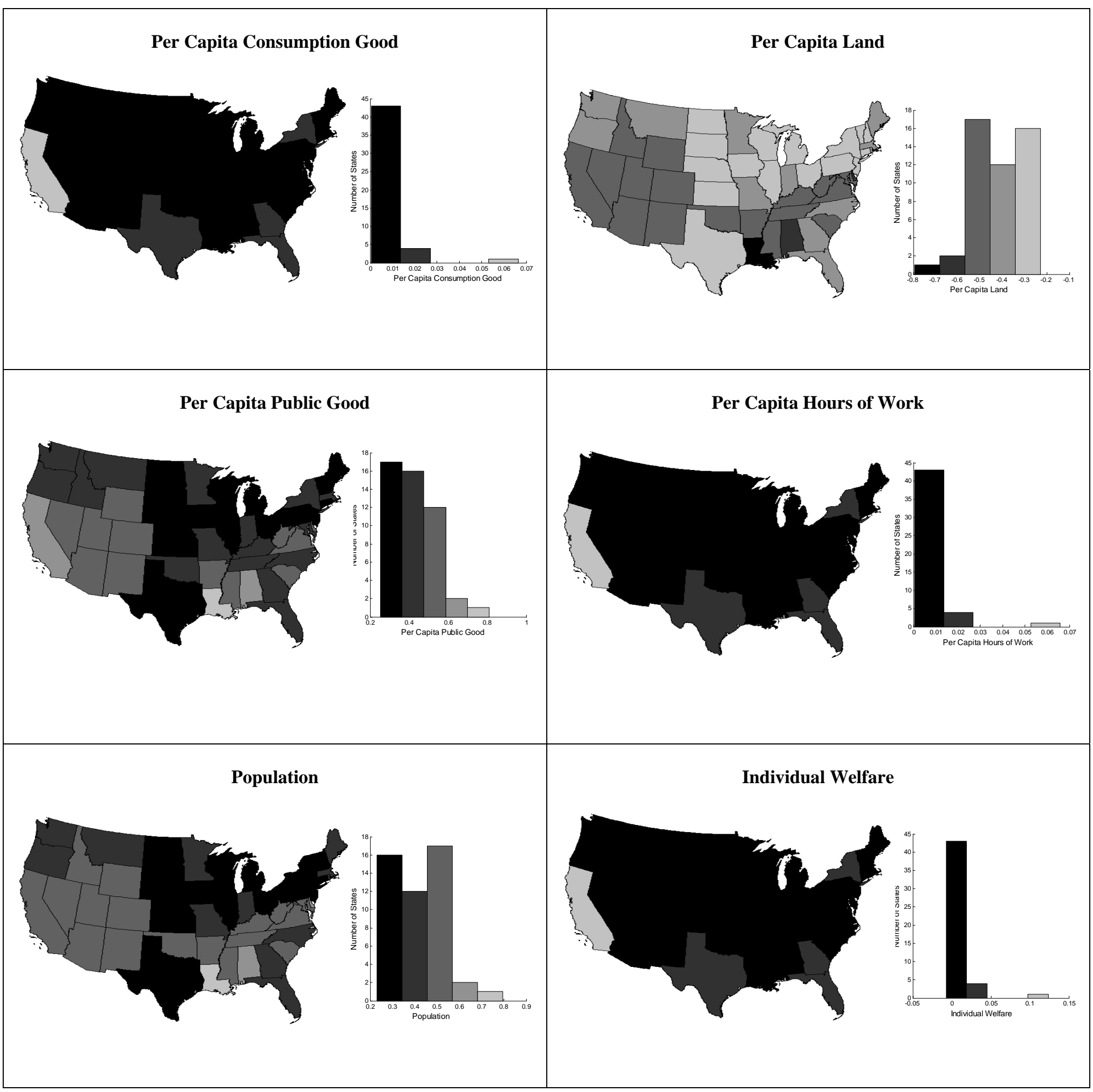


Figure 12 - Elasticities of Endogenous Variables with respect to State-Level Sales Tax Rates

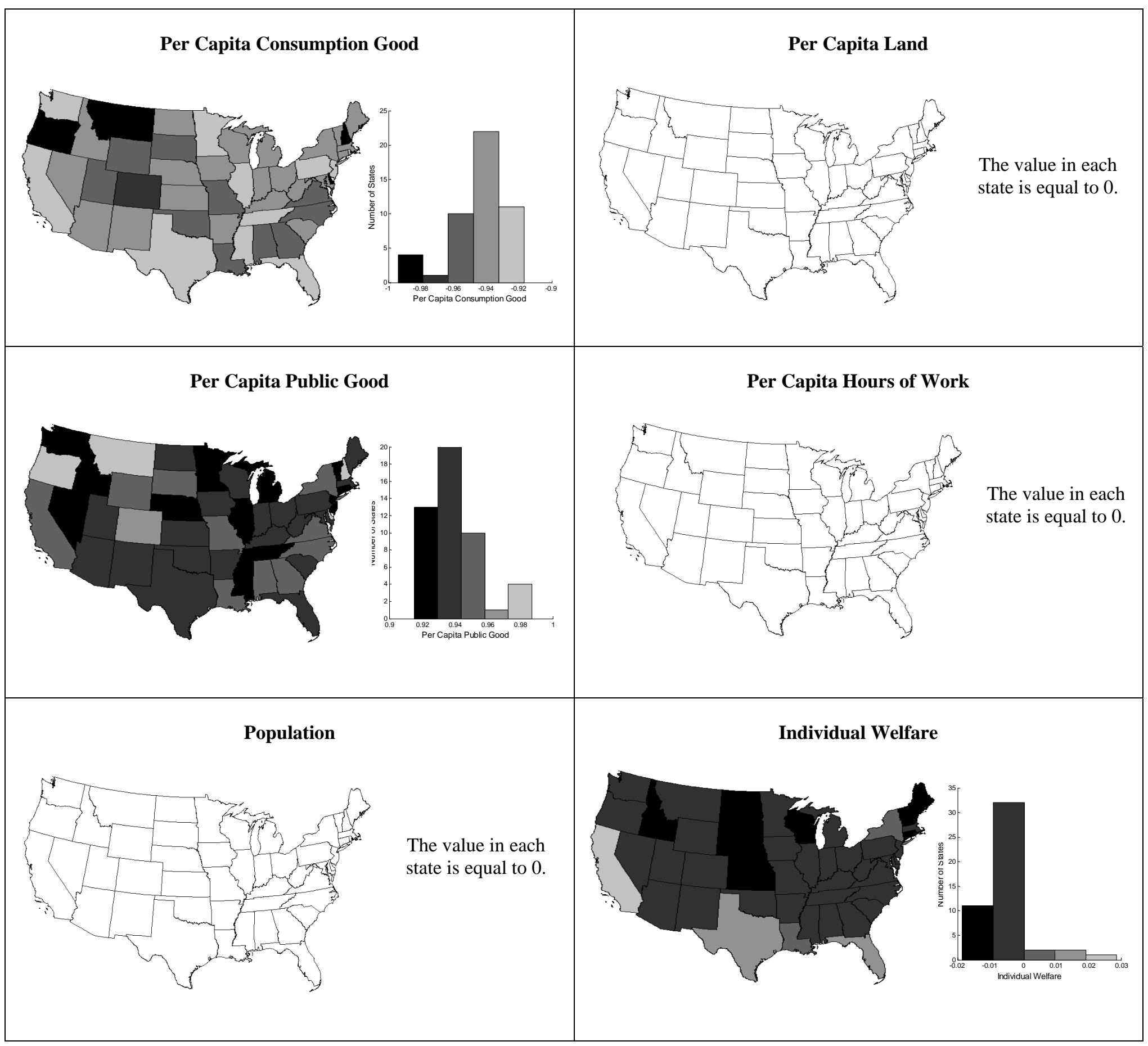

